\title{
Protein Engineering in Structure-Function Studies of Viper's Venom Secreted Phospholipases A2
}

\author{
Toni Petan ${ }^{1}$, Petra Prijatelj Žnidaršič ${ }^{2}$ and Jože Pungerčar ${ }^{1}$ \\ ${ }^{1}$ Department of Molecular and Biomedical Sciences, Jožef Stefan Institute, Ljubljana, \\ ${ }^{2}$ Department of Chemistry and Biochemistry, Faculty of Chemistry and Chemical \\ Technology, University of Ljubljana, Ljubljana, \\ Slovenia
}

\section{Introduction}

Secreted phospholipases $\mathrm{A}_{2}\left(\mathrm{sPLA}_{2} \mathrm{~s}\right)$ constitute a large family of interfacial enzymes that hydrolyze the $s n-2$ ester bond of membrane glycerophospholipids, releasing free fatty acids and lysophospholipids (Murakami et al., 2011). They are abundant in snake venoms, frequently being their major toxic components, and display a variety of pharmacological effects, such as neurotoxicity, myotoxicity, anticoagulant activity, cardiotoxicity and haemolytic activity. The molecular mechanisms underlying these effects are still poorly understood; but they are most probably based on the existence of specific, high-affinity binding sites for toxic sPLA ${ }_{2} \mathrm{~S}$ on the surface of target cells in specific target tissues (Kini, 2003). Snakes have developed, through evolution, an arsenal of structurally similar molecules that target a specific tissue or function, in order to capture and digest their prey. Interestingly, very often a particular $\mathrm{sPLA}_{2}$ molecule may display, despite its simple, globular and compact structure, several different toxic activities. Thus, it significantly expands the possible prey-damaging mechanisms of the venom, which also depend on the type of prey, site of injection of the toxin and the tissue involved. The remarkable variety of pharmacological effects exerted by $\mathrm{sPLA}_{2}$ toxins is a consequence of several factors that have intrigued scientists working in the field, but have also greatly complicated the study of their actions. The complications include (1) the apparently indiscriminate enzymatic activities of sPLA $_{2}$ toxins on different cellular and non-cellular phospholipid membranes and aggregates; (2) the diverse effects of the products of the hydrolysis of $\mathrm{sPLA}_{2}$ toxins, especially on membrane structural integrity and dynamics, thus affecting the major structural and functional features of the cell; and (3) the ever increasing diversity of sPLA intra- and extracellular binding proteins discovered in mammalian tissues, which are involved in very different biological processes. Additionally, many of the actions of sPLA 2 toxins involve complex, multi-step molecular mechanisms, in which a specific combination of enzymatic activity and/or protein binding is probably essential for a particular step. Although $\mathrm{sPLA}_{2} \mathrm{~s}$ are structurally highly conserved proteins, it is clear that subtle evolutionary changes of residues on the surface of the molecule have empowered these enzymes with this wide range of toxic activities. Their ability to recognize specific molecular 
targets has been gradually optimized and thus interferes with a range of physiological processes (Kini \& Chan, 1999). Snakes have even developed, through their evolution, catalytically inactive sPLA $_{2}$-homologues specialized in membrane damage that occurs independently of enzymatic activity (Lomonte et al., 2009). Interestingly, a range of structurally very similar sPLA ${ }_{2}$ enzymes, as well as an enzymatically inactive sPLA 2 homologue, are also present in mammals. The mammalian sPLA 2 family consists of 10 or 11 enzymes (Lambeau \& Gelb, 2008) that display different cell- and tissue-specific expression patterns. The proteins act with a broad range of enzymatic activities on a variety of cellular and non-cellular phospholipid membranes (Murakami et al., 2011). They bind with high affinity to various soluble and membrane protein targets, many of which were discovered using toxic sPLA 2 s (Pungerčar \& Križaj, 2007; Valentin \& Lambeau, 2000). Furthermore, apart from their direct effects on membrane structure and function, the products of their catalysis are precursors of hundreds of bioactive lipid signalling molecules, such as the eicosanoids. The mammalian sPLA 2 enzymes display a similarly broad range of roles, mostly incompletely understood and often contradictory, in various physiological and pathophysiological processes, such as lipid digestion and homeostasis, innate immunity, inflammation, fertility, blood coagulation, asthma, atherosclerosis, autoimmune diseases and cancer (Lambeau \& Gelb, 2008; Murakami et al., 2011). In this they are analogous to their venom counterparts, owing their functions to a combination of enzymatic activity, direct and indirect effects of the products of their hydrolysis, and specific interactions with molecular partners inside or outside the cell. The research on the action of exogenous snake venom sPLA $A_{2}$ enzymes, which target particular physiological processes in their mammalian prey, has been providing important clues for deciphering the biological roles of the mammalian endogenous sPLA 2 enzymes as well (Rouault et al., 2006; Valentin \& Lambeau, 2000).

The most potent $\mathrm{sPLA}_{2}$ toxins display presynaptic (B-)neurotoxicity by attacking the presynaptic site of neuromuscular junctions. The venom of the nose-horned viper, Vipera ammodytes ammodytes, contains three presynaptically neurotoxic sPLA $\mathrm{A}_{2} \mathrm{~S}$, ammodytoxins (Atxs) A, B and C, two non-toxic ammodytins (Atns), AtnI 1 and $\mathrm{AtnI}_{2}$, and a myotoxic and catalytically inactive Ser 49 sPLA $_{2}$ homologue, ammodytin L (AtnL). They are all group IIA $\mathrm{sPLA}_{2} \mathrm{~s}$. The presynaptically acting (B-neurotoxic) Atxs interfere specifically with the release of acetylcholine from motoneurons and cause irreversible blockade of neuromuscular transmission. The exact mechanism of their action is not yet fully understood, but it must include specific binding to receptor(s) on the presynaptic membrane and enzymatic activity (Montecucco et al., 2008; Pungerčar \& Križaj, 2007). The binding to highly specific, and yet unknown, primary molecular targets of ß-neurotoxins (ß-ntxs) on the presynaptic membrane is most probably followed by entry of the toxin into the nerve cell (Logonder et al., 2009; Pražnikar et al., 2008; Rigoni et al., 2008). It has been proposed that different sPLA2toxins exploit different internalization routes (Pungerčar \& Križaj, 2007). In the motoneuron, they may impair the cycling of synaptic vesicles by phospholipid hydrolysis and by binding to specific intracellular protein targets, like calmodulin (Kovačič et al., 2009, 2010; Šribar et al., 2001) and 14-3-3 proteins (Šribar et al., 2003b) in the cytosol, and R25 (Šribar et al., 2003a) in mitochondria. Although the role of enzymatic activity in $\$$-neurotoxicity of $\mathrm{sPLA}_{2} \mathrm{~S}$ is still somewhat controversial, accumulated results speak largely in favour of its being indispensable for full expression of the B-neurotoxic effect (Montecucco et al., 2008; Pungerčar \& Križaj, 2007; Rouault et al., 2006). 
In spite of numerous attempts to identify the surface residues of $\mathrm{sPLA}_{2} \mathrm{~S}$ crucial for a particular pharmacological effect (i.e., the "B-neurotoxic site" or the "anticoagulant site") based initially on structural analysis, chemical modification and, later on, site-directed mutagenesis, the molecular basis of their toxicity has yet to be resolved (Kini, 2003; Križaj, 2011; Pungerčar \& Križaj, 2007; Rouault et al., 2006). We have addressed this issue in studies based on protein engineering of the nosed-horned viper sPLA ${ }_{2} \mathrm{~s}$. These have resulted in more than fifty mutants and chimeric $\mathrm{SPLA}_{2}$ proteins that have been produced and characterized in terms of their biochemical and biological activities (most of them are shown in Table 1). The site-directed mutagenesis studies have provided answers to, or at least significantly improved, our knowledge concerning many important questions regarding the toxic and enzymatic activities of Atxs and other sPLA ${ }_{2} \mathrm{~S}$, such as:

- Which regions of the molecule are important for the ß-neurotoxicity of Atxs and homologous toxic sPLA ${ }_{2} \mathrm{~s}$ ?

- Which surface residues of Atxs are crucial for interaction with their high-affinity binding proteins? Is there a correlation between the affinity for binding to a particular protein target and the neurotoxic potency of Atxs, suggesting a role for the receptor protein in the process?

- Which residues are responsible for interfacial membrane binding of Atxs? How do the interfacial membrane and kinetic properties of Atxs influence their toxic action? How do the enzymatic properties of Atxs compare with those of the best-studied mammalian $\mathrm{sPLA}_{2} \mathrm{~s}$ ?

- What is the importance of the loss in evolution of enzymatic activity in the case of the

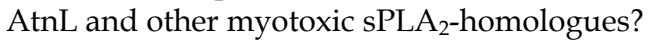

The results obtained have contributed significantly to a better understanding of the molecular mechanisms of action of snake venom $\mathrm{sPLA}_{2} \mathrm{~S}$ and provided clues to the action of the homologous groups of mammalian sPLA $2 \mathrm{~s}$.

\section{Search for the "neurotoxic site" and the role of enzymatic activity}

The significant structural similarities of toxic and non-toxic $\mathrm{sPLA}_{2} \mathrm{~S}$, which differ in their pharmacological actions, have enticed a large number of researchers hoping to find the "holy grail" of sPLA2-toxin research - the toxic site. The site is presumed to comprise only a small number of crucial amino acid residues (Kini, 2003). To explain the wide range of pharmacological effects induced by snake venom sPLA $_{2}$ s, Kini \& Evans (1989) proposed a model comprising specific "target sites" present on the surface of particular cell types. The target sites are proposed to be recognized by complementary "pharmacological sites" on the toxin molecule, these being structurally distinct from, and independent of, the "catalytic site." Thus, high-affinity binding (at least in the nM range) of the toxin to specific target sites ensures that, upon entering the circulation, each toxin binds primarily to its proper target tissue. It is highly likely that the primary target, or acceptor, sites are proteins. This is because of the much lower affinity $\left(\mathrm{mM}-\mu \mathrm{M}\right.$ range) of $\mathrm{sPLA}_{2} \mathrm{~S}$ for binding to the abundant zwitterionic phospholipid surfaces (i.e., cell membranes) (Bezzine et al., 2002; Petan et al., 2005; Singer et al., 2002) and, following enzyme adsorption to the membrane surface, indiscriminate binding to and hydrolysis of phospholipid molecules at the catalytic site. Therefore, separate pharmacological sites on an $\mathrm{sPLA}_{2}$ molecule recognizing different target binding sites should be the main structural determinants that differentiate their respective 
pharmacological actions, such as presynaptic or central neurotoxicity. However, according to the results of our mutagenesis structure-function studies of Atxs reviewed below, it is unlikely that there is a structurally distinct, single "presynaptic neurotoxic site" located in a specific part of the molecule, in contrast to the strict physical localization of the enzyme active site. Rather, different parts of the toxin molecule are likely to be involved in different stages of the complex multi-step process of neurotoxicity, all contributing to the final outcome. In this view, structurally different $B$-ntxs may have different surface regions that bind to different (extra- and intracellular) targets, which are nevertheless involved in the same process, most probably the recycling of synaptic vesicles. However, they all share the nonspecific $\mathrm{SPLA}_{2}$ activity, i.e., the ability to bind and hydrolyze different phospholipid molecules embedded in membranes of various compositions - an essential step in the complete, irreversible blockade of neuromuscular transmission. Therefore, at least in the case of $B$-neurotoxic sPLA $2 \mathrm{~S}$, the use of the term "presynaptic neurotoxic site" appears unsuitable for describing the multiple regions distributed on the surface of the sPLA 2 molecule (Prijatelj et al., 2008).

Given the multi-step, and as yet incompletely known, molecular events leading to presynaptic neurotoxicity of $\mathrm{sPLA}_{2} \mathrm{~s}$, a simple correlation between their in vitro enzymatic activity and their lethal potency would not be expected (Rosenberg, 1997). Indeed, there are numerous examples of $\mathrm{sPLA}_{2}$ B-ntxs with significantly different enzymatic properties, which are, however, not reflected in differences in toxicity; in fact even the most potent sPLA 2 ß-ntxs are weak enzymes (Petan et al., 2005; Pražnikar et al., 2008; Prijatelj et al., 2006b, 2008; Rosenberg, 1997). Nevertheless, sPLA 2 enzymatic activity is necessary for full expression of the ß-neurotoxic effect (Montecucco et al., 2008; Pungerčar \& Križaj, 2007). Its role in the process is most probably obscured by the numerous factors affecting both sPLA 2 activity and neurotoxicity, especially the, as yet unknown, (sub)cellular location, accessibility, composition and physical properties of the target membrane. The enzymatic action of $\mathrm{sPLA}_{2} \mathrm{~S}$ could lead to structural and functional destruction of cell membranes and organelles, like mitochondria or synaptic vesicles (Pražnikar et al., 2008, 2009; Pungerčar \& Križaj, 2007; Rigoni et al., 2008), since the products of phospholipid hydrolysis are disruptive to many physiological processes by impairing the function of peripheral and integral membrane proteins and promoting membrane dysfunction by altering membrane asymmetry, curvature and fusogenicity (Montecucco et al., 2008; Paoli et al., 2009; Rigoni et al., 2005). The apparent lack of correlation between in vitro enzymatic activity and lethal potency of Atxs or other neurotoxic sPLA 2 (Montecucco et al., 2008; Petan et al., 2005; Pungerčar \& Križaj, 2007) can be explained by the strict localization of the sPLA $\mathrm{A}_{2}$ activity to particular target membrane(s) due to binding to highly specific extra- and intracellular protein acceptors (Paoli et al., 2009; Petan et al., 2005; Pungerčar \& Križaj, 2007). Our studies investigating the interfacial binding and kinetic properties of toxic $\mathrm{SPLA}_{2} \mathrm{~S}$ and their mutants have provided important clues to understanding the role of enzymatic activity in the process of presynaptic neurotoxicity of $\mathrm{sPLA}_{2} \mathrm{~s}$. As described in detail below, despite their potent neurotoxic activity, Atxs are quite effective in hydrolysing pure phosphatidylcholine (PC) vesicles as well as PC-rich plasma membranes of mammalian cells, similarly to the most active mammalian group V and X sPLA 2 enzymes (Petan et al., 2005, 2007; Pražnikar et al., 2008). We have also shown that, when tightly bound to the membrane surface, the $\mathrm{Ca}^{2+}$ requirements of Atxs are in the micromolar range (Petan et al., 2005), opening up the possibility that such neurotoxins are also catalytically active in the subcellular 
compartments where $\mathrm{Ca}^{2+}$ concentrations are low (Kovačič et al., 2009; Petan et al., 2005). Moreover, Atxs are rapidly internalized in motoneuronal cells and are, surprisingly, translocated to the cytosol, where they specifically bind calmodulin (CaM) and 14-3-3 proteins, strongly opposing the dogma of the exclusively extracellular action of not only sPLA $_{2}$-neurotoxins, but also of sPLA ${ }_{2}$ in general (Pražnikar et al., 2008). In agreement with these findings, we have recently shown that high-affinity binding to the cytosolic $\mathrm{Ca}^{2+}$ sensor molecule CaM leads to structural stabilization (increased resistance to the reducing environment of the cytosol) and a significant augmentation of the enzymatic activity of Atxs and, intriguingly, also of the mammalian group V and X sPLA 2 s (Kovačič et al., 2009, 2010). These findings strongly support the possibility of augmentation of Atx enzymatic activity by $\mathrm{CaM}$ in the cytosol during the process of ß-neurotoxicity. They also point to a new mechanism of modulating the enzymatic activity of mammalian group $\mathrm{V}$ and $\mathrm{X}_{\mathrm{sPLA}} \mathrm{S}$ or some other non-toxic endogenous sPLA 2 (Kovačič et al., 2010).

\section{Structural determinants of presynaptic neurotoxicity of $\mathrm{sPLA}_{2} \mathrm{~s}$}

The subtlety of the structure-function relationship of sPLA $\mathrm{PL}_{2}$ neurotoxins is obvious on examination of the primary structures and toxicities of Atxs. The three sPLA $\mathrm{A}_{2}$ toxins each consist of 122 amino acid residues and differ at only five positions (Križaj, 2011). AtxC may be considered as a natural double mutant (F124I/K128E) and AtxB as a triple mutant (Y115H/R118M/N119Y) of AtxA. Nevertheless, their lethal potencies in mice differ considerably. AtxA is the most lethal; and its protein isoforms, AtxC and AtxB, are 17- and 28-fold less potent, respectively (Thouin et al., 1982). The crystal structures of recombinant AtxA (PDB code 3G8G) and natural AtxC (PDB code 3G8H) demonstrate the absence of significant structural differences between the two toxins (Saul et al., 2010). There is only a minor conformational difference at positions 127 and 128 in the C-terminal region, caused by the charge-reversal substitution of Lys128 for Glu, which does not significantly influence the toxicity (Saul et al., 2010). An illustrative example of the subtle structure-function relationships of $s \mathrm{PLA}_{2} \mathrm{~S}$ is the conversion, by a single mutation (F22Y), of the gene for bovine pancreatic group IB sPLA 2 to a gene encoding a molecule able to compete with crotoxin, a Bneurotoxic $\mathrm{sPLA}_{2}$ from the South American rattlesnake, Crotalus durissus terrificus, for binding to its $45-\mathrm{kDa}$ neuronal-binding protein. This led the authors to suggest the conversion of the non-toxic pancreatic sPLA 2 to a neurotoxic molecule (Tzeng et al., 1995).

By substituting several basic residues in the C-terminal region (AtxANNTETE mutant: AtxA$\mathrm{K} 108 \mathrm{~N} / \mathrm{K} 111 \mathrm{~N} / \mathrm{K} 127 \mathrm{~T} / \mathrm{K} 128 \mathrm{E} / \mathrm{E} 129 \mathrm{~T} / \mathrm{K} 132 \mathrm{E}$ ) and in the B-structure region (AtxASSL mutant: AtxA-K74S/H76S/R77L) with acidic and non-ionic residues, we have shown, contrary to previous beliefs, that the basic character of Atxs, and probably of other Bneurotoxic $\mathrm{sPLA}_{2} \mathrm{~s}$, is not obligatory for presynaptic toxicity (Ivanovski et al., 2004; Prijatelj et al., 2000; Table 1). According to our earlier structure-function analyses, the more than one order of magnitude lower toxicity of AtxC than that of AtxA is a consequence of the substitution of the aromatic Phe124 by Ile (Pungerčar et al., 1999). Furthermore, in accordance with the three substitutions responsible for the difference in toxicities of AtxA and AtxB, several other C-terminal residues of AtxA, namely the Tyr115/Ile116/ Arg118/Asn119 (YIRN) cluster, were shown to be important for the neurotoxicity of Atxs (Ivanovski et al., 2000). Thus, the lethal potency of the AtxA-Y115K/I116K/R118M/N119L (AtxA ${ }^{\mathrm{KKML}}$ ) mutant was 290-fold lower than that of AtxA (Ivanovski et al., 2000 and Table 1). 


\begin{tabular}{|c|c|c|c|c|c|}
\hline \multirow{2}{*}{ sPLA $_{2}$} & \multirow{2}{*}{$\mathrm{LD}_{50}(\mu \mathrm{g} / \mathrm{kg})$} & \multicolumn{3}{|c|}{$\mathrm{IC}_{50}(\mathrm{nM})$} & \multirow{2}{*}{ References } \\
\hline & & $\mathrm{CaM}$ & R25 & R180 & \\
\hline AtxA & 21 & $6 \pm 2$ & $10 \pm 3$ & $16 \pm 3$ & $a, b$ \\
\hline AtxB & 580 & $23 \pm 4$ & n. d. & n. d. & $a, c$ \\
\hline AtxC & 360 & $21 \pm 3$ & 50 & 155 & $a, c, d, e$ \\
\hline 12-AtxA & 280 & $72 \pm 15$ & $5 \pm 2$ & $>10^{4}$ & $f$ \\
\hline I-AtxA & 500 & $250 \pm 60$ & $3.4 \pm 0.3$ & $>10^{4}$ & $f$ \\
\hline P-AtxA & 420 & $380 \pm 85$ & $3.5 \pm 0.5$ & $>10^{4}$ & $f$ \\
\hline $\mathrm{AtnI}_{2} / \mathrm{AtxA}^{\mathrm{K} 108 \mathrm{~N}}$ & $>10^{4}$ & $1300 \pm 200$ & $20 \pm 6$ & $490 \pm 100$ & $g$ \\
\hline $\mathrm{AtnI}_{2} \mathrm{~N} 24 \mathrm{~F} / \mathrm{Atx} \mathrm{A}^{\mathrm{K} 108 \mathrm{~N}}$ & $>5000$ & $1700 \pm 300$ & $24 \pm 6$ & $850 \pm 200$ & $g$ \\
\hline AtnI 2 & $>10^{4}$ & $>10^{4}$ & $>10^{4}$ & $610 \pm 100$ & $g$ \\
\hline AtxA NNTETE & 660 & $27 \pm 5$ & 16 & 100 & $c, d$ \\
\hline AtxAK108N/K111N & 67 & $17 \pm 4$ & 38 & 68 & $c, d, h$ \\
\hline AtxA $127 \mathrm{~T}$ & 35 & $20 \pm 3$ & 22 & 300 & $c, d$ \\
\hline AtxA $128 \mathrm{E}$ & 45 & $14 \pm 3$ & n. d. & n. d. & $c, h$ \\
\hline Atx $A^{\mathrm{F} 24 \mathrm{~A}}$ & 90 & $7.0 \pm 0.9$ & $15 \pm 1$ & $17 \pm 2$ & $b$ \\
\hline $\operatorname{At} \times A^{F 24 N}$ & 2800 & $5.6 \pm 0.7$ & $14 \pm 2$ & $26 \pm 1$ & $b$ \\
\hline AtxA $\mathrm{A}^{\mathrm{F} 24 \mathrm{~S}}$ & 380 & $7.4 \pm 0.2$ & $14 \pm 1$ & $16 \pm 2$ & $b$ \\
\hline $\operatorname{At} \times A^{\mathrm{F} 24 \mathrm{~W}}$ & 175 & $13.6 \pm 0.3$ & $37 \pm 5$ & $26 \pm 3$ & $b$ \\
\hline AtxA $\mathrm{A}^{\mathrm{F} 24 \mathrm{Y}}$ & 330 & $9.2 \pm 0.9$ & $14 \pm 3$ & $19 \pm 4$ & $b$ \\
\hline $\operatorname{Atx} A^{v 31 W}$ & 135 & n. d. & n. d. & n. d. & $i$ \\
\hline $\operatorname{Atx} A^{R 72 E}$ & 84 & $71 \pm 3$ & $14 \pm 1$ & $78 \pm 7$ & $j$ \\
\hline AtxA $A^{R 72 I}$ & 32 & $17 \pm 2$ & $18.0 \pm 0.4$ & $28 \pm 3$ & $j$ \\
\hline AtxA $\mathrm{A}^{\mathrm{R} 72 \mathrm{~K}}$ & 50 & $46 \pm 2$ & $11.7 \pm 0.4$ & $83 \pm 9$ & $j$ \\
\hline AtxA ${ }^{R 72 S}$ & 55 & $24 \pm 2$ & $16 \pm 1$ & $35 \pm 1$ & $j$ \\
\hline AtxAssL & 276 & $18 \pm 1$ & $18 \pm 1$ & $107 \pm 8$ & $j$ \\
\hline AtxA $\mathrm{A}^{\mathrm{K} 86 \mathrm{~A}}$ & 24 & $8.1 \pm 0.3$ & $15 \pm 1$ & $20 \pm 3$ & $j$ \\
\hline Atx $\mathrm{A}^{\mathrm{K} 86 \mathrm{E}}$ & 32 & $7 \pm 1$ & $18 \pm 1$ & $42 \pm 4$ & $j$ \\
\hline AtxA ${ }^{\mathrm{K} 86 \mathrm{G}}$ & 34 & $7.5 \pm 0.2$ & $12.1 \pm 0.1$ & $65 \pm 4$ & $j$ \\
\hline AtxA $A^{K 86 R}$ & 31 & $8.8 \pm 0.5$ & $16.3 \pm 0.5$ & $36 \pm 1$ & $j$ \\
\hline AtxA KKML & $\sim 6000$ & $50 \pm 9$ & 86 & 257 & $c, k$ \\
\hline $\operatorname{Atx} \mathrm{A}^{\mathrm{KK}}$ & $\sim 5000$ & $21 \pm 3$ & 380 & 118 & $c, k$ \\
\hline AtxA/DPLA ${ }_{2}{ }^{\text {YIRN }}$ & 45 & $27 \pm 5$ & $180 \pm 25$ & $100 \pm 16$ & $l$ \\
\hline AtxA $\mathrm{A}^{\mathrm{KEW}} / \mathrm{DPLA}_{2} \mathrm{YIRN}$ & 910 & $43 \pm 12$ & $110 \pm 15$ & $22 \pm 4$ & $l$ \\
\hline AtxA $\mathrm{KE} / \mathrm{DPLA}_{2} \mathrm{YIRN}$ & 790 & $14 \pm 4$ & $87 \pm 9$ & $24 \pm 4$ & $l$ \\
\hline AtxA ${ }^{\mathrm{W}} / \mathrm{DPLA}_{2} \mathrm{YIRN}^{\mathrm{Y}}$ & 107 & $28 \pm 7$ & $78 \pm 12$ & $19 \pm 5$ & $l$ \\
\hline AtxA/DPLA2 & 2600 & $110 \pm 10$ & $45 \%{ }^{\#}$ & $280 \pm 19$ & $l$ \\
\hline $\mathrm{DPLA}_{2}{ }^{\mathrm{YIRN}}$ & $\sim 17000$ & $43 \pm 14$ & $200 \pm 30$ & $120 \pm 21$ & $c, l$ \\
\hline $\mathrm{DPLA}_{2}$ & 3100 & $300 \pm 36$ & $75 \%{ }^{\#}$ & $300 \pm 45$ & $c, l$ \\
\hline AtnL & $>10000$ & n. d. & n. d. & n. d. & $m$ \\
\hline AtnL YVGD & $>7000$ & n. d. & n. d. & n. d. & $m$ \\
\hline AtnLYWGD & 2200 & n. d. & n. d. & n. d. & $m$ \\
\hline
\end{tabular}

Table 1. Lethal potency and protein-binding affinity of Atxs, Atns, DPLA 2 and their mutants. $\mathrm{IC}_{50}$ values (the concentration of competitor $\mathrm{SPLA}_{2}$ required to reduce the binding of $10 \mathrm{nM}$ 125I-AtxC by 50\%) were determined from competition binding experiments for binding to calmodulin (CaM), the mitochondrial receptor R25 and the neuronal M-type sPLA $_{2}$ receptor, R180. \#The recombinant toxin did not completely inhibit the binding of $125 \mathrm{I}-$ AtxC. ${ }^{a}$ Thouin et al., 1982; $b$ Petan et al., 2002; $c$ Prijatelj et al., 2003; $d$ Prijatelj et al., 2000; $e$ Čopič et al., 1999; fPrijatelj et al., 2006b; 8 Prijatelj et al., 2002; $h$ Pungerčar et al., 1999; $i$ Petan et al., 2005; jIvanovski et al., 2004; kIvanovski et al., 2000; IPrijatelj et al., 2008; mPetan et al., 2007. 
The KKML cluster is present in the weakly neurotoxic DPLA $A_{2}$ from the venom of Russell's viper, Daboia (Vipera) russelii russelii, which shares a high level of amino acid identity (82\%) with AtxA. However, the latter is almost 150-fold more toxic in mice (Prijatelj et al., 2003). To our great surprise, the introduction of the YIRN cluster into DPLA 2 did not increase its toxicity; on the contrary, the DPLA ${ }_{2}{ }^{Y I R N}$ mutant was more than five times less toxic than DPLA $_{2}$ (Prijatelj et al., 2003). Additionally, our study on the importance of the N-terminal residue Phe24, in which it was replaced by other aromatic (tyr or trp), polar uncharged (ser or asn) or hydrophobic (ala) residues, suggested that Phe24 is also involved in the neurotoxicity of Atxs, apparently at a stage not involving enzymatic activity or interactions with the high-affinity binding proteins R25, R180 and CaM (Petan et al., 2002). The aromatic Phe24 was chosen for this study on the basis of several interesting characteristics. It is located in a region immediately preceding the $\mathrm{Ca}^{2+}$-binding loop, but it is spatially close to the important Phe124. It is important for membrane binding as part of the interfacial binding surface (IBS, see below) of the enzyme, and it is replaced by ser in the weakly neurotoxic DPLA 2 . These facts prompted us to propose that a particular combination of both $\mathrm{C}$-terminal and $\mathrm{N}$-terminal residues must be involved in B-neurotoxicity. In order to identify the N-terminal residues that supplement the role of the YIRN cluster in the high neurotoxic potency of AtxA, we selectively mutated some of the remaining residues that differentiate $\mathrm{DPLA}_{2}$ from AtxA. First, we introduced the N-terminal half of AtxA into DPLA $\mathrm{A}_{2}$ by preparing the chimeric AtxA/DPLA 2 protein. Its lethal potency was relatively low, in the range of those of DPLA 2 and the AtxAKKML mutant (Table 1 and Ivanovski et al., 2000), confirming that it is primarily the presence of the KKML cluster in the C-terminus of the chimera that has a strong negative influence on toxicity. Secondly, by substituting the KKML cluster in DPLA 2 with the YIRN cluster of AtxA, we produced a chimeric mutant (AtxA/DPLA 2 YIRN) that is 58 -fold higher in lethal potency than is AtxA/DPLA 2 , reaching a level of toxicity similar to that of the highly neurotoxic AtxA. Thus, only in combination with the N-terminal part of AtxA is the presence of the YIRN cluster sufficient for the high neurotoxic potency of AtxA and AtxA/DPLA 2 YIRN. This allowed us to exclude the importance of the additional eleven C-terminal residues present in AtxA and absent in DPLA $_{2}$ - Thr70, His76, Glu78, Gly85, Arg100, Asn114, Ser130, Glu131 - and was in accordance with the findings of our early mutagenesis study on the three C-terminal lysines at positions 108, 111 and 128 (Pungerčar et al., 1999) (Figure 1). These results clearly confirmed our hypothesis that a particular combination of C-terminal residues, especially those in the region 115-119, i.e., the YIRN cluster, and certain N-terminal residues are necessary for the potent $B$-neurotoxicity of Atxs.

Our next objective was to determine the contribution to the high neurotoxic potency of AtxA of the remaining nine N-terminal residues that differentiate it from DPLA 2 (Met7, Gly11, Asn17, Pro18, Leu19, Thr20, Phe24, Val31 and Ser67). As described above, the importance of the aromatic Phe24 had already been established (Petan et al., 2002). In order to assess the importance of the remaining N-terminal residues, we first substituted Met7, Gly11 and Val31 in the highly toxic chimera AtxA/DPLA ${ }_{2}$ YIRN by the corresponding residues present in $\mathrm{DPLA}_{2}$ - lys, glu and trp, respectively. The mutant protein AtxAKEW/DPLA ${ }_{2}{ }^{\mathrm{YIRN}}$ displayed a 20-fold lower lethal potency than the AtxA/DPLA 2 YIRN chimera, suggesting involvement of the group of residues at positions 7, 11 and 31 in AtxA neurotoxicity. The lethality of the partial mutants, AtxAKE/DPLA ${ }_{2}{ }^{\mathrm{YIRN}}$ and AtxAW/DPLA ${ }_{2} \mathrm{YIRN}^{\mathrm{W}}$ (Table 1), revealed that the contribution of the pair of residues in the N-terminal helix, Met7 and Gly11, to the 


$\begin{array}{lllllll}1 & 10 & 20 & 30 & 40 & 50 & 60\end{array}$

AtxA

SLLEFGMMILG-ETGKNPLTSYSFYGCYCGVGGKGTPKDATDRCCFVHDCCYGNLP--D-C-----S

AtxB

AtxC

$\operatorname{AtxAKKML~}$

$\operatorname{AtxA/DPLA}{ }_{2}$ YIRN

$\operatorname{AtxA}^{\mathrm{KEW} / \mathrm{DPLA}} \mathbf{A}_{2}$ YIRN

AtxA/DPLA 2

DPLA $A_{2}$ YIRN

$\mathrm{DPLA}_{2}$

AtnL

AtnLYVGD

AtnL YWGD

$\operatorname{AtnI}_{2}$

hGIIA

hGV

hGX
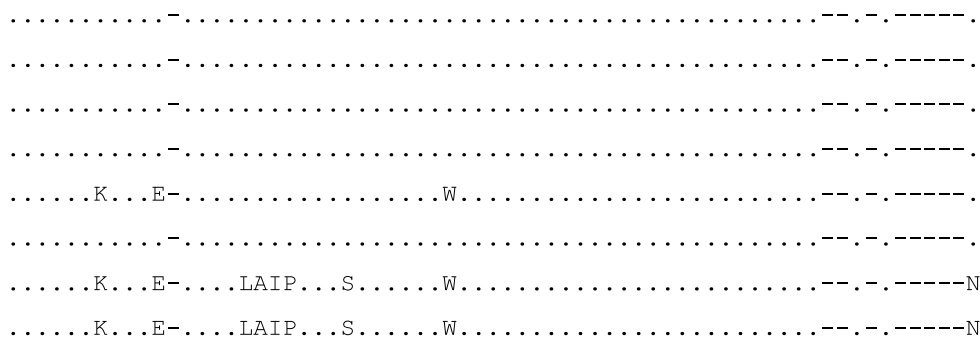

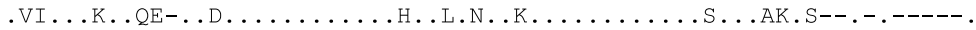

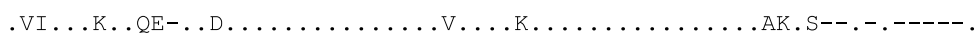

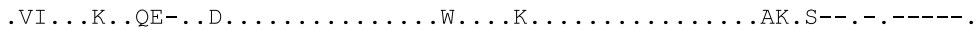

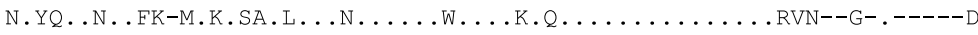

N.VN.HR..KL-T..EAAL. .G...H....R.S......VTT....KR.EKRG-.----G

G..DLKS .EK-V....A..N.G.....W..R....G..W..WA..H..R.EEKG-.-----N

GI . .LAGTVGC-V-.PRTPIA.MK...F..L..H.Q.R..I.W. .HG. . . . TRAEEAG-.----- .

$\begin{array}{llllll}70 & 80 & 90 & 100 & 110 & 120\end{array}$

$\operatorname{AtxA}$

PKTDRYKYHRENGAIVCGK-GTSCENRICECDRAAAICFRKNLKTYNYIYRNYPD-

AtxB

AtxC

AtxAKKML

$\operatorname{AtxA/DPLA}{ }_{2}$ YIRN

$\operatorname{AtxAKEW/DPLA}_{2}$ YIRN

AtxA/DPLA 2

$\operatorname{DPLA}_{2}$ YIRN

DPLA2

AtnL

AtnLYVGD

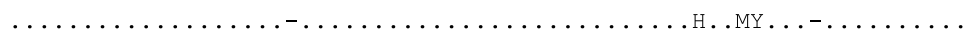

AtnL YWGD

$\operatorname{AtnI}_{2}$

hGIIA

hGV

hGX

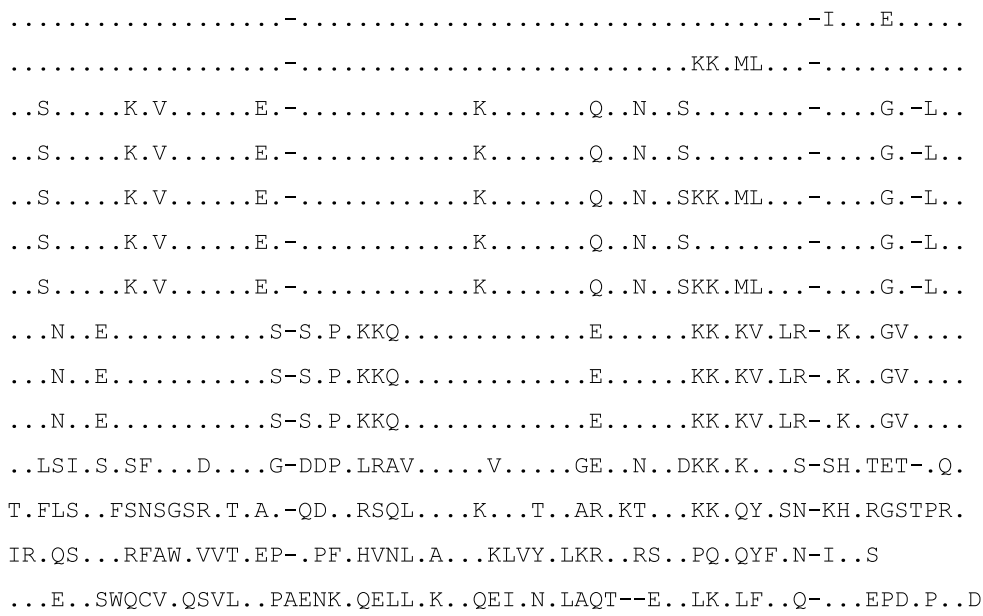

Fig. 1. Amino acid alignment of snake venom group IIA sPLA ${ }_{2} \mathrm{~s}$, including the $\mathrm{sPLA}_{2}-$ homologue ammodytin L (AtnL), some of their mutants and the human group IIA, $\mathrm{V}$ and $\mathrm{X}$ $\mathrm{sPLA}_{2} \mathrm{~s}$. The residues comprising the putative IBS of Atxs are presented in bold type, while those most important for the neurotoxicity of ammodytoxins (Atxs) are underlined. The weakly neurotoxic sPLA 2 from Russell's viper, Daboia r. russelii, DPLA 2 , differs from AtxA in only 22 residues ( $82 \%$ identity). AtnL, the enzymatically inactive but myotoxic Ser 49 
structural homologue of Atxs, displays 74\% amino acid identity with AtxA. The neutral ammodytin $\mathrm{I}_{2}\left(\mathrm{AtnI}_{2}\right)$ is a non-toxic homologue of Atxs from the same venom with $58 \%$ amino acid identity with AtxA. Atxs also display a relatively high degree of identity (48\%) with the human groups IIA (hGIIA), V (hGV) sPLA 2 s, and X (hGX) sPLA 2 (41\%). The common sPLA 2 numbering of residues was used (Renetseder et al., 1985). Gaps, represented by dashes, were used to align the homologous $\mathrm{SPLA}_{2} \mathrm{~S}$ according to conserved residues. Identical amino acid residues are shown by dots. Amino acid single-letter symbols are shown in Table 1 in the chapter by Figurski et al.

neurotoxic potency of AtxA is substantially higher than that of Val31 - in accordance with the negligible effect of the V31W mutation on the lethality of AtxA, despite its outstanding effect on enzymatic activity (Petan et al., 2005). Interestingly, the bulky Trp at position 31 of the AtxA ${ }^{\mathrm{V} 31 \mathrm{~W}}$ and AtxA ${ }^{\mathrm{W}} / \mathrm{DPLA}_{2}{ }^{\mathrm{YIRN}}$ mutants had no significant impact on neurotoxicity, despite being spatially very close to Phe24 and also to the YIRN cluster. The collective contribution of the N-terminal residues Met7, Gly11 and Phe24 to the neurotoxicity of AtxA is very significant and similar to that of the YIRN cluster in the C-terminus. For example, the substitution of Phe24 with ser in AtxA caused an approximately 19-fold decrease in neurotoxicity (Petan et al., 2002), which is similar to the reduction seen after adding the Nterminal region of AtxAKEW, in which the residues Met7, Gly11 and Val31 were substituted with lys, glu and trp, respectively, to DPLA ${ }_{2} \mathrm{YIRN}$, resulting in the AtxAKEW/DPLA 2 YIRN chimeric mutant. Therefore, it is highly likely that the remaining $\mathrm{N}$-terminal residues differentiating AtxA and DPLA2, i.e., the Asn17/Pro18/Leu19/Thr20 cluster and Ser67, are not greatly involved in neurotoxicity.

Our structure-function studies of $B$-neurotoxic sPLA 2 (Ivanovski et al., 2000, 2004; Petan et al., 2002, 2005; Prijatelj et al., 2000, 2002, 2003, 2006b, 2008; Pungerčar et al., 1999) clearly show that different parts of the toxin molecule have separate roles in the distinct steps of the complex mechanism of presynaptic neurotoxicity (Pungerčar \& Križaj, 2007). Most significantly, by selectively mutating parts of the DPLA 2 molecule, we were able to map the residues that separate the weakly $\mathrm{B}$-neurotoxic sPLA $\mathrm{PL}_{2}$ from the 150 -fold more potent AtxA (Prijatelj et al., 2008). In summary, the most important structural features responsible for the high neurotoxic potency of Atxs (Figure 2, A) are: the "upper" part of the molecule concentrated around the C-terminal region 115-119 (the YIRN cluster) and including the spatially close aromatic Phe124 and Phe24, and the N-terminal helix region with the Met7/Gly11 pair in the "lower right" part of the molecule.

\section{Enzymatic activity of Atxs: factors influencing interfacial binding and hydrolysis of phospholipid membranes}

Secreted $\mathrm{PLA}_{2} \mathrm{~S}$ are prototypical interfacial enzymes (Berg et al., 2001). In order to gain access to their phospholipid substrate, $\mathrm{PPLA}_{2} \mathrm{~S}$ first have to bind at the lipid/water membrane interface by their interfacial binding surface (IBS), a group of residues located on a relatively flat exposed region surrounding the entrance to the active site pocket (Lin et al., 1998; Ramirez \& Jain, 1991). Only then, after the enzyme is bound to the surface, can binding of a single phospholipid molecule and its hydrolysis occur in the active site. The catalytic turnover cycle of sPLA ${ }_{2}$ S includes a highly conserved His48-Asp99 dyad and an activated water molecule that acts as a nucleophile during hydrolysis of the $s n-2$ ester bond of the phospholipid (Scott et al., 1990). The resulting tetrahedral intermediate is stabilized by the 
A
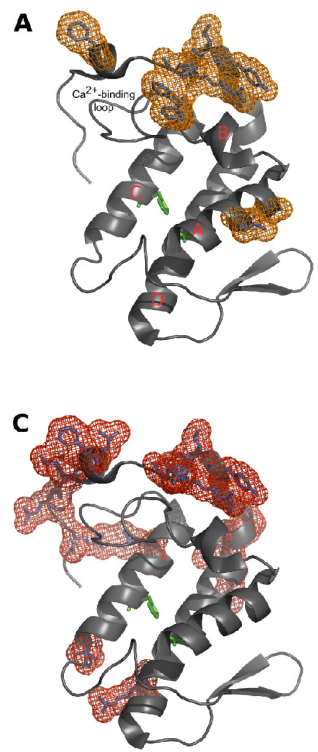

B

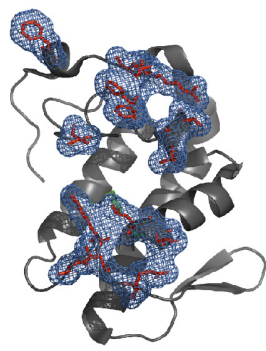

D

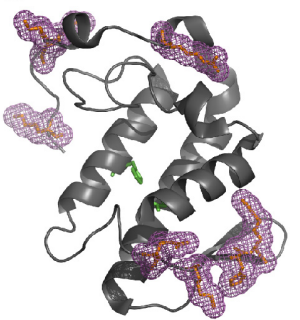

Fig. 2. Surface residues of ammodytoxin A (AtxA) responsible for A) presynaptic neurotoxicity, B) interfacial membrane binding, C) binding to calmodulin and D) binding to factor Xa. The molecule is oriented with the interfacial binding surface (IBS) and the Nterminal residues facing the viewer, while the $\mathrm{C}$-terminal region is located in the upper-left corner of the molecule; and the $B$-structure, in the lower-right corner. A) The conserved sPLA $_{2}$ helical structures are labelled with alphabet letters (red) (see section 4.1 for details; Saul et al., 2010). Residues important for neurotoxicity are presented in orange mesh surface and extend from the C-terminal region 115-119 (the YIRN cluster), including the spatially close aromatic Phe124 and Phe24, to the N-terminal helix region with the Met7/Gly11 pair in the "lower right" part of the molecule. B) The IBS residues of AtxA are presented in blue mesh surface (Leu2, Leu3, Leu19, Thr20, Phe24, Val31, Ser67, Lys69, Thr70, Arg72, Arg118, Asn119 and Phe124) and surround the active site pocket with His48 and Asp99 (presented in green). C) The Atx-CaM interaction surface comprises most of the C-terminal residues of AtxA in the region 108-131 and several basic residues in a-helices $C$ and D (red mesh surface representation; more details in Kovačič et al., 2010). D) The anticoagulant activity of AtxA is a consequence of its binding to factor $\mathrm{Xa}$, which involves mostly basic residues (magenta mesh surface): Arg118, Lys127, Lys128 and Lys132 in the C-terminal end and Arg72, Lys74, His74 and Arg77 in the ß-structure region (Prijatelj et al., 2006a).

$\mathrm{Ca}^{2+}$ cofactor, which is coordinatively bound by three main-chain carbonyl oxygen atoms of residues in the conserved $\mathrm{Ca}^{2+}$-binding loop of the enzyme (Tyr28, Gly30 and Gly32) by two carboxylate oxygen atoms of Asp49, and by two oxygen atoms from the phospholipid substrate (Scott et al., 1990). Calcium ion is required for the initial binding of a phospholipid molecule to the active site of $\mathrm{sPLA}_{2} \mathrm{~s}$ and for the catalytic step, but it is not necessary for adsorption of sPLA 2 s to the membrane (Yu et al., 1993). Given that the binding of sPLA 2 s to a membrane surface is structurally and kinetically independent of the subsequent binding 
and catalytic steps at the active site (Berg et al., 2001), the term substrate specificity in the case of sPLA $_{2} \mathrm{~S}$ is a combination of two independent "specificities": (1) the affinity of the enzyme for binding to a membrane surface, governed by the interaction of the IBS and 20-40 phospholipids on the surface, and (2) the relative velocity of hydrolysis of different phospholipid species by the membrane-bound enzyme that obeys Michaelis-Menten kinetics (Berg et al., 2001; Lambeau \& Gelb, 2008). The latter is determined by many factors influencing the interactions of the substrate molecule in the active site cleft, the rate of the catalytic reaction and the rate of release of the reaction products. In general, the active sites of $\mathrm{sPLA}_{2} \mathrm{~S}$ display low specificity for different phospholipid head-groups and acyl chains (Singer et al., 2002). As a consequence, the physiological functions of some sPLA ${ }_{2}$, e.g., the human group IIA (hGIIA), V (hGV) and X (hGX) enzymes, are significantly influenced or even determined by their different interfacial binding specificities and not by the specificity of their catalytic sites (Beers et al., 2003; Bezzine et al., 2000, 2002; Pan et al., 2002; Singer et al., 2002). Therefore, factors influencing interfacial binding of mammalian and toxic sPLA ${ }_{2} \mathrm{~S}$, such as the composition and physical properties of the membrane, the nature of the IBS of the enzyme, and the concentration of phospholipids that are accessible to the sPLA 2 (Mounier et al., 2004), are crucial determinants of sPLA 2 biological activity.

The IBS of most $\mathrm{sPLA}_{2} \mathrm{~s}$ comprises a ring of conserved hydrophobic residues, whereas, around them and on the edges of the IBS, some polar, basic and acidic residues are present (Petan et al., 2005; Snitko et al., 1997). Given that most sPLA 2 s have high activities on anionic membrane surfaces, it was long thought that electrostatic forces between cationic residues of the enzyme and anionic membrane phospholipids are crucial for the membrane binding and activity of sPLA ${ }_{2}$ (Scott et al., 1994). However, a number of studies have shown that, in fact, hydrophobic, aromatic and hydrogen-bonding interactions account for most of the binding energy, even to negatively charged membrane surfaces (Gelb et al., 1999; Ghomashchi et al., 1998; Lin et al., 1998). Nevertheless, it has been suggested that electrostatic interactions are responsible for proper orientation and initial association of $\mathrm{sPLA}_{2} \mathrm{~s}$ with both anionic and zwitterionic membranes. They may significantly modulate the dynamics of establishing strong hydrophobic interactions, when aliphatic and aromatic residues on the IBS penetrate

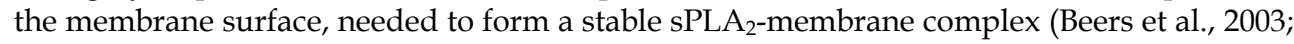
Petan et al., 2005; Prijatelj et al., 2008; Stahelin and Cho, 2001).

\subsection{Basic structural, interfacial kinetic and binding properties of Atxs}

Atxs are highly basic proteins (AtxA has a pI of 10.2, net charge +6), with structural features typical of group IIA sPLA 2 enzymes (Figure 2, A): an N-terminal a-helix A (residues 1-14), a short a-helix B (residues 16-22), a $\mathrm{Ca}^{2+}$-binding loop (residues 25-35), a long a-helix C (residues 39-57), a loop preceding an antiparallel two-stranded $B$-sheet (B-structure; residues 75-78 and 81-84), a long a-helix D (antiparallel to helix C; residues 89-109) and a C-terminal extension (mostly disordered, with two short helical turns; residues 110-133). The active site cleft is buried at the end of a hydrophobic channel (formed by the residues Phe5, Gly6, Tyr22, Ser23, Cys29, Gly30, Ala102, Ala103, Phe106) leading to the highly conserved His48-Asp99 dyad located between the antiparallel a-helices C and D. The entrance to the catalytic site of all $\mathrm{sPLA}_{2} \mathrm{~S}$ is surrounded by the IBS group of residues, forming a relatively flat surface on one side of the molecule that is responsible for membrane binding - the first and prerequisite step in sPLA 2 catalytic action. The IBS of Atxs (Figure 2, B) is formed by Leu2, Leu3, Leu19, Thr20, Phe24, Val31, Ser67, Lys69, Thr70, 
Arg72, Arg118, Asn119, and Phe124 (Petan et al., 2005). The slight structural flexibility observed for the exposed side chains of residues in the IBS (e.g., Phe24 in Figure 2, B) is in keeping with the role of these residues in supporting optimal interactions of the molecule with the dynamic structure of phospholipid aggregates (Saul et al., 2010).

According to the enzymatic activities and membrane-binding affinities of Atxs determined on different phospholipid vesicles, it is clear that these snake venom sPLA $2 \mathrm{~S}$ are very effective in binding to and hydrolyzing different phospholipid membranes (Petan et al., 2005). This property exists despite the fact that they have evolved to be specific and potent neurotoxic molecules and despite the fact that they share striking structural and functional similarities with the mammalian (non-toxic) $\mathrm{sPLA}_{2} \mathrm{~S}$. The enzymatic activities of Atxs on vesicles composed of anionic phosphatidylglycerol (PG), which is, in general, the best sPLA 2 substrate, are comparable to those displayed by the most potent mammalian $\mathrm{SPLA}_{2}$, the pancreatic group IB sPLA 2 , and 5-fold higher than those displayed by the mammalian group IIA sPLA 2 s on these vesicles (Singer et al., 2002). Atxs also have particularly high activities on phosphatidylserine (PS) vesicles, the main anionic phospholipid in eukaryotic membranes, well above the activities of the group IB and IIA sPLA $\mathrm{A}_{2}$ that are the most active mammalian $\mathrm{SPLA}_{2} \mathrm{~s}$ on these vesicles. Most importantly, the activities of Atxs were high also on pure zwitterionic phosphatidylcholine (PC) vesicles, much higher than that of the highly homologous and cationic hGIIA enzyme, which cannot bind to the PC-rich plasma membranes of mammalian cells (Beers et al., 2003; Bezzine et al., 2000, 2002; Birts et al., 2009; Singer et al., 2002). The hGIIA sPLA 2 is well known for its preference for anionic phospholipid substrates and its negligible activity on PC-rich membrane surfaces (Beers et al., 2003; Bezzine et al., 2000, 2002). These properties strongly influence the physiological role of the hGIIA enzyme, for example, by enabling its high antibacterial concentrations in human tears without affecting the corneal epithelial cells (Birts et al., 2009). Although the activities of Atxs were lower than those displayed by group $\mathrm{V}$ and $\mathrm{X} \mathrm{sPLA}_{2} \mathrm{~S}$, which are by far the most potent among the mammalian $\mathrm{PLA}_{2} \mathrm{~S}$ in hydrolyzing PC vesicles and releasing fatty acids from cell membranes (Bezzine et al., 2000, 2002; Singer et al., 2002), they were able to hydrolyze plasma membranes of different intact mammalian cells at a rate that correlated well with their specific activities on PC vesicles (Petan et al., 2005; Pražnikar et al., 2008). The high activity of Atxs on PC-rich vesicles is a consequence of the ability of these venom $\mathrm{sPLA}_{2} \mathrm{~S}$ to bind well to such membrane surfaces, with affinities comparable to those of mammalian group $\mathrm{V}$ and $\mathrm{X} \mathrm{sPLA}_{2} \mathrm{~s}$. Furthermore, unlike the neutral hGX and similarly to the highly cationic hGIIA enzyme, the presence of anionic phospholipids in the membrane surface greatly enhances the membrane-binding affinity of Atxs and consequently the rate of phospholipid hydrolysis (Bezzine et al., 2000, 2002; Petan et al., 2005, 2007). This property may have an important influence on both localization of the toxin to its target membrane and its enzymatic effectiveness in vivo. It is now clear that, when conditions of high affinity binding apply (i.e., binding of hGIIA or Atxs to anionic PG vesicles), sPLA ${ }_{2}$ s reach their halfmaximal enzymatic activities at low micromolar concentrations of $\mathrm{Ca}^{2+}$ (Petan et al., 2005; Singer et al., 2002). The proposed cytosolic action of Atxs (Pražnikar et al., 2008), and most probably other structurally similar $\mathrm{sPLA}_{2} \mathrm{~S}$, is strongly supported by several factors. They may enable the enzymatic activity of Atxs in a reducing environment containing insufficient (nanomolar) concentrations of calcium. In support of this idea are (1) the high degree of stability of AtxA under conditions resembling those in the cytosol of eukaryotic cells (Kovačič et al., 2009; Petrovič et al., 2004), (2) the additional and very significant structural 
stabilization and augmentation of sPLA 2 enzymatic activity by CaM (Kovačič et al., 2009, 2010), (3) the transient cytosolic microdomains of high local calcium concentrations $(\sim 100$ $\mu \mathrm{M})$ (Meldolesi et al., 2002) or calcium entry through the damaged plasmalemma due to $\mathrm{sPLA}_{2}$ action prior to internalization (Montecucco et al., 2008), and (4) the presence of anionic phospholipids (PS) on the cytosolic face of the plasma membrane and internal cellular organelles (Okeley \& Gelb, 2004). In conclusion, Atxs are effective enzymes that bind strongly to and hydrolyze rapidly both anionic and zwitterionic phospholipid aggregates, including mammalian plasma membranes, presenting a broad combination of properties characteristic of different mammalian $\mathrm{sPLA}_{2} \mathrm{~s}$. The potential for the high enzymatic activity of Atxs appears to be at odds with their specific neurotoxic action. However, it is in line with the possible limitations imposed on their intracellular activity on a particular target membrane by the harsh conditions in the cytosol during the process of neuromuscular transmission blockade.

\subsection{Role of different IBS residues in supporting interfacial binding and activity of Atxs}

The presence of tryptophan on the IBS of different sPLA $2 \mathrm{~s}$ is a well-known determinant of their ability to bind with high affinity and hydrolyze PC-rich membranes, crucially influencing their biological roles. Its role has been highlighted in the cases of the hGV and hGX enzymes (Bezzine et al., 2002; Han et al., 1999), the acidic sPLA 2 from Naja naja atra snake venom (Sumandea et al., 1999), a range of mutants of hGIIA (Beers et al., 2003) and the pancreatic group IB sPLA 2 s (Lee et al., 1996). Despite the fact that Atxs do not contain a Trp residue, they display a relatively high activity on PC vesicles. Furthermore, the substitution of Val31 by Trp led to a dramatic 27-fold increase in the activity of AtxA (Petan et al., 2005), reaching a level of activity on PC-rich vesicles higher than those of hGV and $\mathrm{hGX}$ and in the range of the best-acting snake venom sPLA $\mathrm{S}_{2}$, e.g., the cobra venom sPLA 2 (Sumandea et al., 1999). However, despite its very high affinity for PC-rich surfaces and its order of magnitude higher potency in releasing fatty acids from plasma membranes of intact HEK293 cells, C2C12 myocytes and motoneuronal NSC34 cells (Pražnikar et al., 2008), the AtxA-V31W mutant did not display a major change in neurotoxic potency in vivo. This again highlights the dependence of the toxicity of sPLA $\mathrm{P}_{2} \mathrm{~B}$-ntxs on a combination of toxin-acceptor interactions leading to localization of the toxin to the target membrane at which the enzymatic activity of AtxA is sufficient for the observed effects. In contrast, the same substitution, V31W, on the IBS of the enzymatically active quaternary mutant AtnL YVGD of the myotoxic Atx homologue, AtnL (see below), caused a 100-fold increase in its activity on PC vesicles, as well as a significant increase in its toxicity in vivo and in vitro (Petan et al., 2007). Thus, in the case of the enzymatically active mutants of AtnL, the correlation between enzymatic activity on PC membranes and toxicity in vivo suggests that the mechanism of their toxicity differs from that used by Atxs and that it depends largely on their interfacial binding affinity and enzymatic activity on PC-rich target membranes, both of which are significantly affected by Trp31 (Petan et al., 2007).

The role of aromatic residues in the interfacial binding of sPLA 25 depends to a high degree on the nature of the residue itself, its position on the IBS and the orientation of its side-chain (Stahelin \& Cho, 2001; Sumandea et al., 1999). This is evident from the fact that the substitution of Phe 24 with Trp did not cause a substantial increase in enzymatic activity or interfacial binding affinity of AtxA (Petan et al., 2002, 2005) or hGIIA (Beers et al., 2003). 
Thus, both Phe and Trp can have similar roles in interfacial binding, despite the differences in their interactions with the membrane: the highly amphiphilic Trp favours partitioning in the interfacial phospholipid head group region of the bilayer (Yau et al., 1998), while the aromatic Phe penetrates deeper into the hydrophobic core of the phospholipid acyl chains (Stahelin \& Cho, 2001; Sumandea et al., 1999). In the case of AtxA and hGIIA, Trp31 is obviously in a much better position to influence interfacial binding than is Trp24. Additionally, AtxA and AtxA $\mathrm{A}^{\mathrm{F} 24 \mathrm{~W}}$ display higher activities and binding affinities than do the F24S, F24Y and F24N mutants on PC-rich vesicles containing anionic phospholipids. Although the structures of Trp and Phe differ significantly, both are obviously better suited to take advantage of the presence of anionic phospholipid in the interface than the polar Ser, Asn and even the aromatic Tyr. The importance of non-polar interactions in interfacial binding to negatively charged surfaces is also clear in the case of AtxB, AtxAKKML and AtxAv31W. These molecules already display very high activities on PC vesicles containing $10 \%$ PS (10\% PS/PC vesicles), and they reach the level of maximal activity already on $30 \%$ PS/PC vesicles, indicating that the enzymes are fully bound to these vesicles (Petan et al., 2005). In general, we have observed the greatest increases in activity upon introduction of $10 \%$ anionic phospholipids (PS or PG) into PC vesicles for mutants that have numbers of hydrophobic and aromatic residues on their IBS similar to or higher than those in AtxA. Besides providing the basis for electrostatic interactions, the presence of anionic phospholipids in PC vesicles may facilitate non-polar interactions as a result of membrane perturbation (Buckland \& Wilton, 2000).

Despite the remarkable impact of Trp at position 31 on interfacial binding of Atxs and other sPLA $_{2}$ s, such as hGIIA (Beers et al., 2003), our subsequent site-directed mutagenesis studies revealed that the positive influence of Trp on membrane binding of $\mathrm{sPLA}_{2} \mathrm{~S}$ may be significantly diminished, depending on the delicate balance of contributions of each IBS residue to interfacial binding. While Atxs and hGIIA sPLA ${ }_{2}$ do not contain a Trp on their IBS, $\mathrm{DPLA}_{2}$, a weakly neurotoxic sPLA 2 from Russell's viper that differs from AtxA in only 22 residues, has a Trp residue at position 31 and yet displays interfacial binding and kinetic properties similar to those of AtxA (Petan et al., 2005; Prijatelj et al., 2003, 2008). Besides V31W, DPLA 2 contains several other substitutions of equivalent AtxA IBS residues: L19I, T20P, F24S, S67N, T70S, R118M and N119L (Petan et al., 2005; Prijatelj et al., 2008). By analysing the properties of a range of AtxA/DPLA 2 mutants and chimeras (Prijatelj et al., 2008), we were able to pinpoint the IBS residues that are crucial for the intriguing differences in interfacial binding and activity of AtxA and DPLA2. Not surprisingly, the introduction of Trp31 to the AtxA/DPLA ${ }_{2}$ YIRN chimera (see Figure 1 for sequence data) caused a very significant 50 -fold increase in the rate of hydrolysis of PC vesicles. However, the impact of the same Trp residue, when introduced along with two additional substitutions, producing the AtxA ${ }^{\mathrm{KEW}} / \mathrm{DPLA}_{2}{ }^{\mathrm{YIRN}}$ mutant, was almost completely abolished, resulting in a low level of activity on PC vesicles, only 2 to 4 -fold higher than those of AtxA/DPLA ${ }_{2}$ YIRN, AtxA and DPLA 2 . These results clearly confirmed our earlier suggestion (Petan et al., 2005) that the well-known positive impact of Trp31 on the interfacial binding and enzymatic activity of mammalian and venom $\mathrm{sPLA}_{2} \mathrm{~S}$ is, to a large extent, counterbalanced by the presence of Lys7 and Glu11 on the edges of the IBS in the case of DPLA $_{2}$, instead of the hydrophobic Met7 and nonpolar Gly11 in AtxA. This is most probably a consequence of altered orientation of DPLA 2 on the membrane, due to strong electrostatic interactions between Lys7 and Glu11 and the zwitterionic membrane surface, 
which prevents the productive interaction of Trp31, and thus DPLA 2 , with the interface. Similarly, two basic residues at nearly equivalent positions in the hGIIA enzyme, Arg7 and Lys10, were shown to have a negative influence on interfacial binding (Bezzine et al., 2002; Snitko et al., 1997). In agreement with this, we have shown that the substitution of Arg at position 72 of the IBS of Atxs and DPLA 2 has a positive impact on interfacial binding and activity only upon introduction of a hydrophobic (Ile), but not a polar (Ser), acidic (Glu) or other basic (Lys) residue (Ivanovski et al., 2004). An additional, albeit smaller, negative effect on interfacial binding and enzymatic activity of DPLA $\mathrm{D}_{2}$ is provided by the presence of the polar residue Ser24 instead of the aromatic and hydrophobic Phe in AtxA (Petan et al., 2002, 2005). However, there are several residues on the IBS of DPLA ${ }_{2}$, but not Atxs, that significantly improve its interfacial binding and activity. The YIRN cluster in the C-terminal part of AtxA, shown to be important for its neurotoxic effect (Ivanovski et al., 2000), contains the hydrophilic IBS residues Arg118 and Asn119, while the hydrophobic Tyr115 and Ile116 are not part of the presumed IBS. The introduction of the YIRN cluster into DPLA 2 , instead of its KKML cluster, or into the various AtxA/DPLA 2 variants, resulted in a substantial decrease of the initial rates of hydrolysis of charge-neutral PC vesicles (Table 2). Therefore, the presence of a hydrophobic or aromatic IBS residue at positions 118 and 119 has a significant positive influence on interfacial binding to anionic and, particularly, zwitterionic phospholipid surfaces. Accordingly, this positive impact is evident in the case of Met118 and Leu119 in DPLA ${ }_{2}$ and the AtxAKKML mutant, as well as of Met118 and Tyr119 in AtxB, in contrast to the hydrophilic Arg118 and Asn119 in AtxA and mutants containing the YIRN cluster (Ivanovski et al., 2000; Petan et al., 2005; Prijatelj et al., 2003, 2008). Considering the similar activities on PC-rich vesicles displayed by AtxB and the AtxAKKML mutant, it is obvious that the roles of Tyr and Leu at position 119 are in fact very similar. This indicates that the removal of the polar cluster Arg118/Asn119 from AtxA has a greater positive effect on interfacial binding than the aromatic or hydrophobic nature of the substituting residue at position 119, which is in accordance with the negligible impact of the substitution Y119W on interfacial binding of hGIIA sPLA 2 to 1,2-dioleoyl-sn-glycero-3-phosphocholine (DOPC) vesicles (Beers et al., 2003). Thus, the role of aromatic residues, including Trp, in interfacial binding of sPLA $2 \mathrm{~s}$, depends strongly, as well as on their nature, position on the IBS, and side-chain orientation, on the counterbalancing effects of polar/electrostatic interactions provided by hydrophilic/charged residues on or near the IBS. In conclusion, the most significant differences in interfacial binding and enzymatic activity of AtxA and DPLA 2 are therefore a consequence of the natural substitutions that have led to significant changes in the hydrophobic/aromatic character of residues on or near the IBS - M7K, G11E, F24S, V31W, R118M and N119L.

\section{Interaction of Atxs with high-affinity binding proteins}

Several high-affinity binding proteins for Atxs have been identified in porcine cerebral cortex. Two of these are membrane proteins of $25 \mathrm{kDa}$ (R25) and $180 \mathrm{kDa}$ (R180). R25, which is located in the mitochondrial membrane (Šribar et al., 2003a), binds only Atxs (Vučemilo et al., 1998), whereas R180, identified as the plasma membrane M-type sPLA 2 receptor $\left(\mathrm{sPLA}_{2} \mathrm{R}\right)$, binds both toxic and non-toxic $\mathrm{sPLA}_{2} \mathrm{~s}$ of groups IB and IIA (Čopič et al., 1999; Vardjan et al., 2001). Surprisingly, several cytosolic, high-affinity binding proteins for Atxs were identified as well - calmodulin (CaM) (Šribar et al., 2001), the $\gamma$ and 


\begin{tabular}{|c|c|c|c|c|c|}
\hline \multirow{2}{*}{ sPLA $_{2}$} & \multicolumn{5}{|c|}{ Specific activity $(\mu \mathrm{mol} /(\mathrm{min} \times \mathrm{mg}))$} \\
\hline & POPG & POPS & POPC & 10\% POPS/POPC & $30 \%$ POPS/POPC \\
\hline AtxA & $1042 \pm 160$ & $1251 \pm 188$ & $3.8 \pm 0.5$ & $56 \pm 6$ & $450 \pm 21$ \\
\hline AtxB & $1149 \pm 34$ & $1189 \pm 153$ & $14 \pm 2$ & $240 \pm 22$ & $1133 \pm 150$ \\
\hline AtxC & $1116 \pm 91$ & $477 \pm 101$ & $1.9 \pm 0.2$ & $14.0 \pm 1.3$ & $166 \pm 21$ \\
\hline $\operatorname{AtnI}_{2}$ & $1070 \pm 150$ & $57 \pm 5$ & $12.3 \pm 1.7$ & $49 \pm 2$ & $159 \pm 16$ \\
\hline AtxAKKML & $1148 \pm 126$ & $1252 \pm 40$ & $19 \pm 1$ & $400 \pm 22$ & $1322 \pm 42$ \\
\hline AtxA $\mathrm{v} 31 \mathrm{~W}$ & $2102 \pm 88$ & $1964 \pm 154$ & $102 \pm 7$ & $525 \pm 28$ & $1957 \pm 36$ \\
\hline AtxA $\mathrm{A}^{\mathrm{F} 24 \mathrm{~W}}$ & $914 \pm 43$ & $906 \pm 56$ & $4.4 \pm 0.5$ & $50 \pm 1$ & $209 \pm 6$ \\
\hline $\operatorname{Atx} \mathrm{A}^{\mathrm{F} 24 \mathrm{Y}}$ & $822 \pm 41$ & $1304 \pm 102$ & $2.1 \pm 0.1$ & $9.5 \pm 0.5$ & $163 \pm 11$ \\
\hline AtxA $A^{F 24 N}$ & $780 \pm 29$ & $535 \pm 43$ & $1.09 \pm 0.03$ & $5.1 \pm 0.5$ & $68 \pm 3$ \\
\hline $\operatorname{Atx} \mathrm{A}^{\mathrm{F} 24 \mathrm{~A}}$ & $813 \pm 107$ & $1291 \pm 65$ & $1.2 \pm 0.1$ & $4.4 \pm 0.3$ & $92 \pm 5$ \\
\hline $\operatorname{Atx} A^{F 24 S}$ & $400 \pm 73$ & $430 \pm 42$ & $0.71 \pm 0.06$ & $4.4 \pm 0.1$ & $24 \pm 4$ \\
\hline AtxA $A^{R 72 E}$ & $438 \pm 26$ & n. d. & $0.33 \pm 0.07$ & n. d. & n. d. \\
\hline $\operatorname{Atx} A^{R 72 I}$ & $1655 \pm 108$ & n. d. & $6.9 \pm 0.8$ & n. d. & n. d. \\
\hline AtxA $A^{R 72 K}$ & $686 \pm 102$ & n. d. & $1.2 \pm 0.1$ & n. d. & n. d. \\
\hline AtxA $\mathrm{A}^{\mathrm{R} 72 \mathrm{~S}}$ & $800 \pm 82$ & n. d. & $1.6 \pm 0.3$ & n. d. & n. d. \\
\hline $\mathrm{DPLA}_{2}$ & $1600 \pm 130$ & $1195 \pm 47$ & $1.1 \pm 0.1$ & $88 \pm 9$ & $442 \pm 31$ \\
\hline $\mathrm{DPLA}_{2} \mathrm{YIRN}$ & $1100 \pm 120$ & $996 \pm 129$ & $0.07 \pm 0.02$ & $4.2 \pm 0.4$ & $141 \pm 20$ \\
\hline AtxA/DPLA ${ }_{2}$ & $1300 \pm 140$ & n. d. & $3.14 \pm 0.05$ & n. d. & n. d. \\
\hline AtxA $\mathrm{AEW}^{\mathrm{KEW}} / \mathrm{DPLA}_{2}{ }^{\mathrm{YIRN}}$ & $1200 \pm 170$ & n. d. & $2.2 \pm 0.5$ & n. d. & n. d. \\
\hline AtxA $\mathrm{KE} / \mathrm{DPLA}_{2} \mathrm{YIRN}$ & $830 \pm 80$ & n. d. & $0.14 \pm 0.01$ & n. d. & n. d. \\
\hline $\operatorname{AtxA}^{W} / \mathrm{DPLA}_{2}{ }^{\mathrm{YIRN}}$ & $1900 \pm 210$ & n. d. & $26 \pm 3$ & n. d. & n. d. \\
\hline AtxA/DPLA ${ }_{2}{ }^{Y I R N}$ & $1000 \pm 120$ & n. d. & $0.53 \pm 0.06$ & n. d. & n. d. \\
\hline AtnL & No activity & No activity & No activity & n. d. & n. d. \\
\hline AtnLYVGD & $225 \pm 35$ & $91 \pm 7$ & $\sim 0.005$ & $0.49 \pm 0.04$ & $43 \pm 2$ \\
\hline AtnL YWGD & $180 \pm 25$ & $89 \pm 10$ & $0.22 \pm 0.03$ & $8.3 \pm 0.3$ & $96 \pm 5$ \\
\hline 12-AtxA & $5.2 \pm 0.7$ & n. d. & $0.76 \pm 0.06$ & n. d. & n. d. \\
\hline I-AtxA & $4.0 \pm 0.2$ & n. d. & $0.96 \pm 0.04$ & n. d. & n. d. \\
\hline P-AtxA & $1.29 \pm 0.04$ & n. d. & $0.13 \pm 0.03$ & n. d. & n. d. \\
\hline hGIIA & $220 \pm 90$ & $40 \pm 18$ & Lag, $0.7 \pm 0.2$ & n. d. & n. d. \\
\hline hGX & $14 \pm 0.8$ & $4 \pm 2$ & $30 \pm 0.2$ & n. d. & n. d. \\
\hline
\end{tabular}

Table 2. Specific enzymatic activity of $\mathrm{SPLA}_{2} \mathrm{~S}$ on phospholipid vesicles. The specific enzymatic activities were determined on extruded phospholipid vesicles composed of 1palmitoyl-2-oleoyl-sn-glycero-3-phosphocholine (POPC), 1-palmitoyl-2-oleoyl-sn-glycero-3phosphoserine (POPS), 1-palmitoyl-2-oleoyl-sn-glycero-3-phosphoglycerol (POPG), and on vesicles with mixed compositions as stated (in molar percentage) in the Table. The initial rates of phospholipid hydrolysis were measured using a sensitive fluorescence, fatty acid displacement assay; the enzymatic activities were calculated after calibrating the responses with known amounts of oleic acid (Petan et al., 2005). The enzymatic activity value for each $\mathrm{sPLA}_{2}$ is the mean \pm S.D. of at least five independent measurements. Data taken from Ivanovski et al. (2004), Petan et al. (2005, 2007), Prijatelj et al. (2006b, 2008), and Singer et al. (2002).

$\varepsilon$ isoforms of 14-3-3 proteins (Šribar et al., 2003b), and protein disulphide isomerase (Šribar et al., 2005). This suggests the possibility of not only intracellular, but also cytosolic, action of Atxs and other sPLA ${ }_{2}$. They have since been shown to be surprisingly stable in the reducing environment of the eukaryotic cytosol. They are enzymatically active at low micromolar concentrations of $\mathrm{Ca}^{2+}$ ions, and they are also structurally stabilized and activated by binding to CaM (Kovačič et al., 2009, 2010; Petan et al., 2005; Petrovič et al., 
2005). Atxs were also found to bind factor Xa (FXa) and display anticoagulant activity (Prijatelj et al., 2006a). Given that the topic of neuronal high-affinity binding proteins for Atxs and their putative roles in ß-neurotoxicity has been reviewed recently (Pungerčar \& Križaj, 2007), here we only summarize the results obtained with a range of Atx mutants for binding to CaM, R25, FXa and the M-type sPLA 2 receptor.

\subsection{The C-terminal region of Atxs has a novel calmodulin binding motif}

Our protein engineering and competition binding studies using a range of Atxs, DPLA 2 and $\mathrm{AtnI}_{2}$ mutants and chimeras, as well as synthetic peptides corresponding to different regions of Atxs, ultimately resulted in the identification of a novel binding motif for the ubiquitous, highly conserved $\mathrm{Ca}^{2+}$-sensor CaM (Kovačič et al., 2010; Prijatelj et al., 2003). The C-terminal region of AtxA, with a distinctive hydrophobic patch within the region 107-125 surrounded by several basic residues, was identified as the most important element for binding to the $\mathrm{N}$ terminal methionine-rich pocket of $\mathrm{CaM}$ in its $\mathrm{Ca}^{2+}$-induced dumbbell conformation. This work was based on the intriguing 150-fold lower lethal potency and the correspondingly 50fold lower CaM-binding affinity of DPLA ${ }_{2}$ compared to AtxA (Prijatelj et al., 2003). Most notably, the DPLA ${ }_{2}$ YIRN mutant, containing the C-terminal YIRN cluster of AtxA (see above and Figure 1), displayed a 7-fold increase in binding affinity for CaM, only 7-fold lower than that of AtxA. This result suggested a major role of this region for the interaction with CaM. On the other hand, introduction of the whole N-terminal half of AtxA to DPLA 2 and DPLA $_{2}{ }^{\text {YIRN }}$ caused only a slight, 2 to 3-fold increase in binding affinities for CaM, suggesting that the N-terminal part of AtxA has only a supporting role in the binding and is probably located on the periphery of the CaM binding site (Prijatelj et al., 2008). Very recently, we confirmed unambiguously the crucial importance of the C-terminal region of Atxs in CaM binding by building several three-dimensional structural models of sPLA $\mathrm{A}_{2}-\mathrm{CaM}$ complexes, based on AtxA-CaM interaction site mapping, our previous mutagenesis data and proteindocking algorithms (Kovačič et al., 2010). According to the model, the closed conformation of CaM forms a "clamp" around AtxA, with most of the C-terminal residues of AtxA in the region 108-131 being in direct contact with CaM (Figure 2, C). There are only a few additional, but important, contacts between the proteins, formed mainly by basic residues in a-helices C (Arg43 and Asn54) and D (Arg94, Lys108, Asn109 and Lys111) of AtxA. Importantly, the model was validated by superimposing the structures of several mammalian sPLA $2 \mathrm{~S}$ on that of AtxA in the complex and correctly predicting the favourable interactions of group $\mathrm{V}$ and $\mathrm{X}$ mammalian $\mathrm{sPLA}_{2} \mathrm{~S}$ and $\mathrm{CaM}$. The model also showed the basis for the unfavourable interactions, which prevented complex formation between the structurally very similar mammalian group IB and IIA sPLA 25 and CaM. Formation of the complexes was confirmed by competition binding experiments and the augmentation of the enzymatic activity of those $\mathrm{SPLA}_{2} \mathrm{~s}$ interacting with CaM. Most importantly, we have clearly demonstrated that $\mathrm{CaM}$ stabilizes and protects Atxs from denaturation in the reducing environment of the cell cytosol and acts as a non-essential activator of Atxs and of the mammalian group $\mathrm{V}$ and $\mathrm{X}$ sPLA 2 . The fact that CaM-binding results in stabilization and augmentation of enzymatic activity of $\mathrm{sPLA}_{2} \mathrm{~S}$, ranging from the neurotoxic Atxs to the mammalian group $\mathrm{V}$ and $\mathrm{X}$ sPLA $_{2} \mathrm{~S}$, suggests a novel role for $\mathrm{CaM}$ as a regulator of the intracellular actions of some toxic and non-toxic sPLA $2 \mathrm{~s}$, which may be active even in the reducing environment of the cytosol (Kovačič et al., 2009, 2010). The significance of CaM$\mathrm{sPLA}_{2}$ interactions in the pharmacological and (patho)physiological roles of $\mathrm{sPLA}_{2} \mathrm{~s}$ remain to be confirmed. 


\subsection{The $\mathrm{N}$ - and $\mathrm{C}$-terminal regions of Atxs are involved in binding to the neuronal $\mathrm{M}$ - type $S P L A_{2}$ receptor (R180)}

The M-type sPLA 2 receptor, which was cloned and revealed as a member of the C-type lectin superfamily, has been well-characterized and is currently the best-known sPLA 2 binding target. It was shown recently that the M-type receptor is involved in regulating cell senescence (Augert et al., 2009) and is the main antigen target in autoimmune human membranous nephropathy (Beck et al., 2009). However, the pathophysiological implications of the interaction between the M-type sPLA ${ }_{2}$ receptors and both toxic and non-toxic sPLA $\mathrm{S}_{2}$ in general are intriguing and still unknown (Lambeau \& Gelb, 2008; Pungerčar \& Križaj, 2007; Rouault et al., 2006). Although it has been suggested that the neuronal M-type sPLA 2 receptor located on the plasma membrane could be responsible for specific targeting and internalization of $\mathrm{SPLA}_{2}$ neurotoxins in presynaptic nerve terminals, the results of our mutagenesis studies have shown that it may not be involved in the neurotoxicity of Atxs (Prijatelj et al., 2006b). In order to prevent the interaction between AtxA and the receptor, we prepared three mutants of AtxA, containing either the 12-amino acid-long peptide ARIRARGSIEGR, named 12-AtxA, or one each of two variants of a shorter 5-amino acid peptide (ASIGQ and ASPGQ; named I-AtxA and P-AtxA, respectively) fused to the Nterminus of AtxA. These peptides are similar to the $\mathrm{N}$-terminal propeptides present in proenzymes of mammalian group IB (e.g., DSGISPR in human pancreatic proPLA $A_{2}$ ) and group $\mathrm{X} \mathrm{sPLA}_{2} \mathrm{~S}$ (e.g., EASRILRVHRR in the human proenzyme), which do not bind to the M-type sPLA 2 receptor (Hanasaki \& Arita, 2002; Lambeau et al., 1995). The presence of the fusion peptides in AtxA indeed completely abolished the interaction of the toxin with the M-type receptor. However, the mutants displayed only one order of magnitude lower lethality in mice and were able to induce neurotoxic effects on a mouse phrenic nervehemidiaphragm preparation (see Table 1). Although the N-terminal fusion peptides acted effectively as "propeptides" for AtxA and lowered specific enzymatic activity to $\sim 1 \%$ of the wild-type enzyme, their similar neurotoxic profiles on the neuromuscular junction indicate that minimal enzymatic activity suffices for presynaptic toxicity of $\mathrm{sPLA}_{2} \mathrm{~s}$. Additionally, antibodies targeting the sPLA $\mathrm{A}_{2}$-binding C-type lectin-like domain 5 of the M-type sPLA receptor were unable to abolish the neurotoxic action of AtxA on the neuromuscular preparation. Thus, the interaction of AtxA with the neuronal M-type sPLA 2 receptor, R180, is apparently not essential for its presynaptic neurotoxicity. Since we performed the binding experiments with the N-terminal fusion AtxA mutants, using porcine $\mathrm{SLA}_{2}$ receptor, the question still remains as to whether the fusion peptides would also abolish the binding of AtxA to the mouse R180 receptor.

Nevertheless, our site-directed mutagenesis studies have provided important information about the parts of the AtxA molecule involved in binding to R180. Interestingly, the Cterminal YIRN cluster, which is essential for neurotoxicity and binding to CaM and R25, appears to be involved in binding to R180 as well. The first clues were provided by the lower affinity of the AtxAKKML mutant and DPLA 2 for binding to R180 (Ivanovski et al., 2000). (Both contain KKML instead of the YIRN cluster.) The higher binding affinity of mutants containing the YIRN cluster (DPLA ${ }_{2}{ }^{\mathrm{YIRN}}$ or AtxA/DPLA 2 YIRN) confirmed that it is an important part of the AtxA/R180 interaction surface. However, other parts of the molecule also contribute considerably to the binding affinity of AtxA. Interestingly, the Nterminal part of AtxA in the chimera AtxA/DPLA $A_{2}$ did not increase the binding affinity of $\mathrm{DPLA}_{2}$ to R180. However, the introduction of three N-terminal DPLA ${ }_{2}$ residues $(\mathrm{K}, \mathrm{E}$ 
and/or W) to AtxA/DPLA 2 YIRN caused an increase in the binding affinity for R180 up to the level of AtxA, confirming the expected involvement of the N-terminal part of the molecule in binding to R180 as well. Therefore, the interaction surface of AtxA with its neuronal M-type receptor, R180, extends from the C-terminal top of the molecule, across the area close to the $\mathrm{Ca}^{2+}$-binding loop and the IBS, reaching the N-terminal helix on the edges of the IBS.

\subsection{Atxs bind to the mitochondrial receptor R25 through their C-terminal region}

The C-terminal region of Atxs appears to be essential also for binding to the, as yet unidentified, mitochondrial membrane receptor R25. The affinities for binding of the chimeric mutants to R25 ranged from that of the non-toxic AtnI 2 , which does not bind to R25, to those of AtxA, AtnI $2 / A t x A^{K 108 N}$ and $\mathrm{AtnI}_{2}{ }^{\mathrm{N} 24 \mathrm{~F}} / \mathrm{Atx} \mathrm{A}^{\mathrm{K} 108 \mathrm{~N}}$, which were similar to that of AtxA (Prijatelj et al., 2002). Additionally, substitutions of Phe24 in the N-terminal part of AtxA had a negligible effect on its affinity for R25, but nevertheless indicated that this residue is in the vicinity of the toxin-receptor binding surface, most probably located in the C-terminal part of AtxA (Petan et al., 2002). Furthermore, while DPLA D $_{2}$ and the chimera AtxA/DPLA 2 could not completely inhibit the binding of AtxC to R25 in competition binding experiments, the substitution of their KKML cluster with the YIRN cluster led to complete inhibition with a relatively high binding affinity. This implies that residues in the region 115-119 are very important for effective binding to R25, which is apparently present in multiple isoforms. However, the complete inhibition of binding of radiolabelled At $x \mathrm{C}$ to R25 by the AtxAKKML mutant, in contrast to $\mathrm{DPLA}_{2}$ and AtxA/DPLA ${ }_{2}$, indicated that the interaction surface extends beyond the $\mathrm{C}$-terminal region. Indeed there was a slight increase in binding affinity upon introduction of the N-terminal Lys7, Glu11 and/or Trp31 of DPLA 2 to the AtxA/DPLA ${ }_{2}$ YIRN chimera (K, E and/or W; Table 1). While our site-directed mutagenesis and competition binding studies have so far revealed a central role for the Cterminal residues of Atxs in high affinity binding to R25, the interaction surface probably extends beyond the C-terminal region.

\subsection{Atxs exert anticoagulant effects by binding to factor $\mathrm{Xa}$}

In the analysis of non-neurotoxic effects of Atxs, our study of an array of site-directed mutants (Prijatelj et al., 2006a) showed that basic residues in the C-terminal and ß-structure regions are important for AtxA binding to human blood coagulation factor Xa (Figure 2, D). Hence, AtxA has anticoagulant activity. In addition, the 10-fold lower affinity of AtxC for factor $\mathrm{Xa}$, in comparison with AtxA, is due to the (natural) charge-reversal substitution of Lys128 by Glu, leading to a small local conformational change in the C-terminal end of AtxC, which perturbs the interaction with factor Xa (Saul et al., 2010).

\section{Restoration of enzymatic activity reduces the $\mathrm{Ca}^{2+}$-independent membrane damage induced by the myotoxic ammodytin $\mathrm{L}$}

Ammodytin L (AtnL) is a myotoxic and enzymatically inactive structural homologue of Atxs (Petan et al., 2007; Pungerčar et al., 1990). The main structural feature of snake venom sPLA $\mathrm{A}_{2}$-like myotoxins is the substitution of the highly-conserved aspartic acid residue at position 49 , effectively preventing $\mathrm{Ca}^{2+}$ binding and thus abolishing catalytic 
activity (Petan et al., 2007; Ward et al., 2002). The most common substitution is Lys, but AtnL is one of the two known Ser 49 sPLA $_{2}$ homologues. In addition to this replacement, several other substitutions of highly-conserved residues in the enzymatically inactive sPLA $_{2} \mathrm{~S}$ are found concentrated in the region of the $\mathrm{Ca}^{2+}$-binding loop, where the carbonyl oxygen atoms of Tyr28, Gly30 and Gly32 provide three additional coordinative bonds for $\mathrm{Ca}^{2+}$-binding. The myotoxic activity of the Lys49 $\mathrm{sPLA}_{2} \mathrm{~S}$, as well as of the Ser49-containing AtnL, is best characterized by their ability to induce myonecrosis in vivo and show a potent $\mathrm{Ca}^{2+}$-independent membrane-damaging activity in vitro (Lomonte et al., 2009). Although the involvement of a skeletal muscle protein acceptor in the process of sPLA $\mathrm{S}_{2}$-induced myotoxicity cannot be ruled out, a considerable body of evidence has been accumulated indicating that the myotoxic effects are a consequence of a $\mathrm{Ca}^{2+}$-independent protein-lipid interaction that causes direct damage of the plasma membrane of target muscle cells and may allow entry of extracellular $\mathrm{Ca}^{2+}$ and irreversible cell damage (Cintra-Francischinelli et al., 2010; Lomonte et al., 2009; Rufini et al., 1992). The calcium-independent, and thus enzymatic activity-independent, mechanism of membrane damage is also supported by experiments in which inhibition of certain enzymatically active Asp49 myotoxic sPLA ${ }_{2} \mathrm{~S}$ did not eliminate their myotoxic activity (Soares et al., 2001).

We recently described the first example of restoration of activity in AtnL or in any enzymatically inactive Ser49/Lys49 sPLA 2 homologue (Petan et al., 2007). We prepared two enzymatically active quaternary mutants of AtnL (H28Y/L31V,W/N33G/S49D), differing at position 31. Although Asn33 is not directly involved in $\mathrm{Ca}^{2+}$ coordination, we suspected that it might have a negative impact on the optimal local structure of the $\mathrm{Ca}^{2+}$-binding loop. We therefore replaced it with a glycine residue, which is very often found at this position in catalytically active sPLA ${ }_{2} \mathrm{~S}$, as well as in Atxs. Val31 was present in the AtnL YVGD mutant in order to recreate the $\mathrm{Ca}^{2+}$-binding loop of Atxs, while the AtnL YWGD mutant had Trp31 in order to enhance its membrane binding affinity, and thus enzymatic activity, as previously shown in the case of the AtxA $\mathrm{A}^{\mathrm{V} 31 \mathrm{~W}}$ mutant described above. The successful restoration of enzymatic activity by such a small number of substitutions indicates that, apart from the residues involved in $\mathrm{Ca}^{2+}$ coordination, the remainder of the substrate-binding and catalytic network of AtnL is very well conserved. Apparently, in evolution, Lys49 and Ser49 sPLA 2 myotoxins have lost their $\mathrm{Ca}^{2+}$-binding ability and enzymatic activity through subtle changes in the $\mathrm{Ca}^{2+}$-binding network alone, without affecting the rest of the catalytic machinery. Our results strongly suggest that these changes were selected for their $\mathrm{Ca}^{2+}$ independent membrane-damaging ability and increase the specificity of their myotoxic activity. Although the restoration of enzymatic activity in AtnL increased its cytotoxic potency and lethality in general, it had a negative effect on its $\mathrm{Ca}^{2+}$-independent mechanism of membrane damage and on its ability to specifically target differentiated muscle cells in vitro. Given that AtnL shares a high level of identity with AtxA (74\%), it was not surprising that the enzymatically active mutants of AtnL displayed a combination of the properties of both toxins. In other words, the restoration of enzymatic activity of AtnL reduced its ability to act as a potent and specific myotoxic molecule. The latter supports the idea of an evolutionary specialization of Ser49/Lys49 sPLA $_{2}$ homologues to perform the role of abundant and weakly lethal, but specific, muscle-targeting toxins in the arsenal of pharmacologically active molecules found in snake venom. 


\section{Future perspectives}

Recently, we have been able to introduce a free cysteine residue into the molecule of AtxA by substituting Asn79 by Cys at the turn of the antiparallel B-sheet. This mutation allowed for specific labelling of the neurotoxin molecule by either fluorescent or nanogold probes (Pražnikar et al., 2008, 2009). The conjugates were less toxic than the wild-type toxin, but retained its basic properties. They have proved to be a valuable tool in the study of presynaptic neurotoxicity. As an illustration, we have provided evidence that AtxA, a neurotoxic snake venom sPLA 2 is indeed internalized into mammalian (mouse) motor nerve terminals (Logonder et al., 2009).

We believe that similar approaches can be used in further protein engineering of Atxs and also other ß-ntxs, especially in monitoring their trafficking and cellular action (enzymatic activity, binding to protein target molecules). This should finally lead to a complete understanding of the molecular mechanism of presynaptic toxicity of sPLA 2 neurotoxins, which may also open the way for better medical treatment of snake envenomation. Moreover, similar research approaches can also be exploited in the studies of homologous mammalian $\mathrm{sPLA}_{2} \mathrm{~S}$ whose biological roles are still to be clarified.

\section{Acknowledgment}

The authors wish to thank Dr Roger H. Pain for critical reading of the manuscript.

\section{References}

Augert, A., Payré, C., De Launoit, Y., Gil, J., Lambeau, G. \& Bernard, D. (2009). The M-type receptor $\mathrm{PLA}_{2} \mathrm{R}$ regulates senescence through the p53 pathway. EMBO Reports, Vol. 10, No. 3, pp. 271-277

Beck, L.H., Bonegio, R.G.B., Lambeau, G., Beck, D.M., Powell, D.W., Cummins, T.D., Klein, J.B. \& Salant, D.J. (2009). M-type phospholipase $\mathrm{A}_{2}$ receptor as target antigen in idiopathic membranous nephropathy. New England Journal of Medicine, Vol. 361, No. 1, pp. 11-21

Beers, S.A., Buckland, A.G., Giles, N., Gelb, M.H. \& Wilton, D.C. (2003). Effect of tryptophan insertions on the properties of the human group IIA phospholipase $\mathrm{A}_{2}$ : Mutagenesis produces an enzyme with characteristics similar to those of the human group V phospholipase $\mathrm{A}_{2}$. Biochemistry, Vol. 42, No. 24, pp. 7326-7338

Berg, O.G., Gelb, M.H., Tsai, M.D. \& Jain, M.K. (2001). Interfacial enzymology: The secreted phospholipase A2-paradigm. Chemical Reviews, Vol. 101, No. 9, pp. 2613-2654

Bezzine, S., Koduri, R.S., Valentin, E., Murakami, M., Kudo, I., Ghomashchi, F., Sadilek, M., Lambeau, G. \& Gelb, M.H. (2000). Exogenously added human group X secreted phospholipase $\mathrm{A}_{2}$ but not the group IB, IIA, and $\mathrm{V}$ enzymes efficiently release arachidonic acid from adherent mammalian cells. Journal of Biological Chemistry, Vol. 275, No. 5, pp. 3179-3191

Bezzine, S., Bollinger, J.G., Singer, A.G., Veatch, S.L., Keller, S.L. \& Gelb, M.H. (2002). On the binding preference of human groups IIA and $X$ phospholipases $A_{2}$ for membranes with anionic phospholipids. Journal of Biological Chemistry, Vol. 277, No. 50, pp. 48523-48534 
Birts, C.N., Barton, C.H. \& Wilton, D.C. (2010). Catalytic and non-catalytic functions of human IIA phospholipase $\mathrm{A}_{2}$. Trends in Biochemical Sciences, Vol. 35, No. 1, pp. 28-35

Buckland, A.G. \& Wilton, D.C. (2000). Anionic phospholipids, interfacial binding and the regulation of cell functions. Biochimica et Biophysica Acta, Vol. 1483, No. 2, pp. 199-216

Cintra-Francischinelli, M., Pizzo, P., Angulo, Y., Gutiérrez, J.M., Montecucco, C. \& Lomonte, B. (2010). The C-terminal region of a Lys49 myotoxin mediates $\mathrm{Ca}^{2+}$ influx in C2C12 myotubes. Toxicon, Vol. 55, No. 2-3, pp. 590-596

Čopič, A., Vučemilo, N., Gubenšek, F. \& Križaj, I. (1999). Identification and purification of a novel receptor for secretory phospholipase $\mathrm{A}_{2}$ in porcine cerebral cortex. Journal of Biological Chemistry, Vol. 274, No. 37, pp. 26315-26320

Gelb, M.H., Cho, W. \& Wilton, D.C. (1999). Interfacial binding of secreted phospholipases $\mathrm{A}_{2}$ : More than electrostatics and a major role for tryptophan. Current Opinion in Structural Biology, Vol. 9, No. 4, pp. 428-432

Ghomashchi, F., Lin, Y., Hixon, M.S., Yu, B.Z., Annand, R., Jain, M.K. \& Gelb, M.H. (1998). Interfacial recognition by bee venom phospholipase $\mathrm{A}_{2}$ : Insights into nonelectrostatic molecular determinants by charge reversal mutagenesis. Biochemistry, Vol. 37, No. 19, pp. 6697-6710

Han, S.K., Kim, K.P., Koduri, R., Bittova, L., Munoz, N.M., Leff, A.R., Wilton, D.C., Gelb, M.H. \& Cho, W. (1999). Roles of Trp31 in high membrane binding and proinflammatory activity of human group $\mathrm{V}$ phospholipase $\mathrm{A}_{2}$. Journal of Biological Chemistry, Vol. 274, No. 17, pp. 11881-11888

Hanasaki, K. \& Arita, H. (2002). Phospholipase $A_{2}$ receptor: A regulator of biological functions of secretory phospholipase $\mathrm{A}_{2}$. Prostaglandins $\mathcal{E}$ Other Lipid Mediators, Vol. 68-69, pp. 71-82

Ivanovski, G., Čopič, A., Križaj, I., Gubenšek, F. \& Pungerčar, J. (2000). The amino acid region 115-119 of ammodytoxins plays an important role in neurotoxicity. Biochemical and Biophysical Research Communications, Vol. 276, No. 3, pp. 1229-1234

Ivanovski, G., Petan, T., Križaj, I., Gelb, M.H., Gubenšek, F. \& Pungerčar, J. (2004). Basic amino acid residues in the $B$-structure region contribute, but not critically, to presynaptic neurotoxicity of ammodytoxin A. Biochimica et Biophysica Acta, Vol. 1702, No. 2, pp. 217-225

Kini, R.M. \& Evans, H.J. (1989). A model to explain the pharmacological effects of snake venom phospholipases $A_{2}$. Toxicon, Vol. 27, No. 6, pp. 613-635

Kini, R.M. \& Chan, Y.M. (1999). Accelerated evolution and molecular surface of venom phospholipase $\mathrm{A}_{2}$ enzymes. Journal of Molecular Evolution, Vol. 48, No. 2, pp. 125132

Kini, R.M. (2003). Excitement ahead: Structure, function and mechanism of snake venom phospholipase $\mathrm{A}_{2}$ enzymes. Toxicon, Vol. 42, No. 8, pp. 827-840

Kovačič, L., Novinec, M., Petan, T., Baici, A. \& Križaj, I. (2009). Calmodulin is a nonessential activator of secretory phospholipase A2. Biochemistry, Vol. 48, No. 47, pp. 1131911328

Kovačič, L., Novinec, M., Petan, T. \& Križaj, I. (2010). Structural basis of the significant calmodulin-induced increase in the enzymatic activity of secreted phospholipases A2. Protein Engineering, Design \& Selection, Vol. 23, No. 6, pp. 479-487

Križaj, I. (2011). Ammodytoxin: A window into understanding presynaptic toxicity of secreted phospholipases $\mathrm{A}_{2}$ and more. Toxicon, Vol. 58, No. 3, pp. 219-229

Lambeau, G., Ancian, P., Nicolas, J.P., Beiboer, S.H., Moinier, D., Verheij, H. \& Lazdunski, M. (1995). Structural elements of secretory phospholipases $A_{2}$ involved in the 
binding to M-type receptors. Journal of Biological Chemistry, Vol. 270, No. 10, pp. 5534-5540

Lambeau, G. \& Gelb, M.H. (2008). Biochemistry and physiology of mammalian secreted phospholipases A2. Annual Review of Biochemistry, Vol. 77, pp. 495-520

Lee, B.I., Yoon, E.T. \& Cho, W. (1996). Roles of surface hydrophobic residues in the interfacial catalysis of bovine pancreatic phospholipase $\mathrm{A}_{2}$. Biochemistry, Vol. 35, No. 13, pp. 4231-4240

Lin, Y., Nielsen, R., Murray, D., Hubbell, W.L., Mailer, C., Robinson, B.H. \& Gelb, M.H. (1998). Docking phospholipase $A_{2}$ on membranes using electrostatic potentialmodulated spin relaxation magnetic resonance. Science, Vol. 279, No. 5358, pp. 1925-1929

Logonder, U., Jenko-Pražnikar, Z., Scott-Davey, T., Pungerčar, J., Križaj, I. \& Harris, J.B. (2009). Ultrastructural evidence for the uptake of a neurotoxic snake venom phospholipase $\mathrm{A}_{2}$ into mammalian motor nerve terminals. Experimental Neurology, Vol. 219, No. 2, pp. 591-594

Lomonte, B., Angulo, Y., Sasa, M. \& Gutiérrez, J.M. (2009). The phospholipase $\mathrm{A}_{2}$ homologues of snake venoms: Biological activities and their possible adaptive roles. Protein and Peptide Letters, Vol. 16, No. 8, pp. 860-876

Meldolesi, J. (2002). Rapidly exchanging $\mathrm{Ca}^{2+}$ stores: Ubiquitous partners of surface channels in neurons. News in Physiological Sciences, Vol. 17, pp. 144-149

Montecucco, C., Gutiérrez, J.M. \& Lomonte, B. (2008). Cellular pathology induced by snake venom phospholipase $\mathrm{A}_{2}$ myotoxins and neurotoxins: Common aspects of their mechanisms of action. Cellular and Molecular Life Sciences, Vol. 65, No. 18, pp. 2897-2912

Mounier, C.M., Ghomashchi, F., Lindsay, M.R., James, S., Singer, A.G., Parton, R.G. \& Gelb, M.H. (2004). Arachidonic acid release from mammalian cells transfected with human groups IIA and $X$ secreted phospholipase $A_{2}$ occurs predominantly during the secretory process and with the involvement of cytosolic phospholipase $\mathrm{A}_{2}$ - $\mathrm{a}$. Journal of Biological Chemistry, Vol. 279, No. 24, pp. 25024-25038

Murakami, M., Taketomi, Y., Miki, Y., Sato, H., Hirabayashi, T. \& Yamamoto, K. (2011). Recent progress in phospholipase $\mathrm{A}_{2}$ research: From cells to animals to humans. Progress in Lipid Research, Vol. 50, No. 2, pp. 152-192

Okeley, N.M. \& Gelb, M.H. (2004). A designed probe for acidic phospholipids reveals the unique enriched anionic character of the cytosolic face of the mammalian plasma membrane. Journal of Biological Chemistry, Vol. 279, No. 21, pp. 21833-21840

Pan, Y.H., Yu, B.-Z., Singer, A.G., Ghomashchi, F., Lambeau, G., Gelb, M.H., Jain, M.K. \& Bahnson, B.J. (2002). Crystal structure of human group $X$ secreted phospholipase $\mathrm{A}_{2}$. Electrostatically neutral interfacial surface targets zwitterionic membranes. Journal of Biological Chemistry, Vol. 277, No. 32, pp. 29086-29093

Paoli, M., Rigoni, M., Koster, G., Rossetto, O., Montecucco, C. \& Postle, A.D. (2009). Mass spectrometry analysis of the phospholipase $\mathrm{A}_{2}$ activity of snake pre-synaptic neurotoxins in cultured neurons. Journal of Neurochemistry, Vol. 111, No. 3, pp. 737744

Petan, T., Križaj, I., Gubenšek, F. \& Pungerčar, J. (2002). Phenylalanine-24 in the N-terminal region of ammodytoxins is important for both enzymic activity and presynaptic toxicity. Biochemical Journal, Vol. 363, Pt. 2, pp. 353-358

Petan, T., Križaj, I., Gelb, M.H. \& Pungerčar, J. (2005). Ammodytoxins, potent presynaptic neurotoxins, are also highly efficient phospholipase $\mathrm{A}_{2}$ enzymes. Biochemistry, Vol. 44, No. 37, pp. 12535-12545 
Petan, T., Križaj, I. \& Pungerčar, J. (2007). Restoration of enzymatic activity in a Ser-49 phospholipase $\mathrm{A}_{2}$ homologue decreases its $\mathrm{Ca}^{2+}$-independent membrane-damaging activity and increases its toxicity. Biochemistry, Vol. 46, No. 44, pp. 12795-12809

Petrovič, U., Šribar, J., Pariš, A., Rupnik, M., Kržan, M., Vardjan, N., Gubenšek, F., Zorec, R. \& Križaj, I. (2004). Ammodytoxin, a neurotoxic secreted phospholipase $A_{2}$, can act in the cytosol of the nerve cell. Biochemical and Biophysical Research Communications, Vol. 324, No. 3, pp. 981-985

Petrovič, U., Šribar, J., Matis, M., Anderluh, G., Peter-Katalinić, J., Križaj, I. \& Gubenšek, F. (2005). Ammodytoxin, a secretory phospholipase $A_{2}$, inhibits G2 cell-cycle arrest in the yeast Saccharomyces cerevisiae. Biochemical Journal, Vol. 391, Pt. 2, pp. 383-388

Pražnikar, Z.J., Kovačič, L., Rowan, E.G., Romih, R., Rusmini, P., Poletti, A., Križaj, I. \& Pungerčar, J. (2008). A presynaptically toxic secreted phospholipase $\mathrm{A}_{2}$ is internalized into motoneuron-like cells where it is rapidly translocated into the cytosol. Biochimica et Biophysica Acta, Vol. 1783, No. 6, pp. 1129-1139

Pražnikar, Z.J., Petan, T. \& Pungerčar, J. (2009). A neurotoxic secretory phospholipase $\mathrm{A}_{2}$ induces apoptosis in motoneuron-like cells. Annals of the New York Academy of Sciences, Vol. 1152, pp. 215-224

Prijatelj, P., Čopič, A., Križaj, I., Gubenšek, F. \& Pungerčar, J. (2000). Charge reversal of ammodytoxin A, a phospholipase $\mathrm{A}_{2}$-toxin, does not abolish its neurotoxicity. Biochemical Journal, Vol. 352, Pt. 2, pp. 251-255

Prijatelj, P., Križaj, I., Kralj, B., Gubenšek, F. \& Pungerčar, J. (2002). The C-terminal region of ammodytoxins is important but not sufficient for neurotoxicity. European Journal of Biochemistry, Vol. 269, No. 23, pp. 5759-5764

Prijatelj, P., Šribar, J., Ivanovski, G., Križaj, I., Gubenšek, F. \& Pungerčar, J. (2003). Identification of a novel binding site for calmodulin in ammodytoxin A, a neurotoxic group IIA phospholipase $\mathrm{A}_{2}$. European Journal of Biochemistry, Vol. 270, No. 14, pp. 3018-3025

Prijatelj, P., Charnay, M., Ivanovski, G., Jenko, Z., Pungerčar, J., Križaj, I. \& Faure, G. (2006a). The C-terminal and $B$-wing regions of ammodytoxin $A$, a neurotoxic phospholipase $\mathrm{A}_{2}$ from Vipera ammodytes ammodytes, are critical for binding to factor Xa and for anticoagulant effect. Biochimie, Vol. 88, No. 1, pp. 69-76

Prijatelj, P., Vardjan, N., Rowan, E.G., Križaj, I. \& Pungerčar, J. (2006b). Binding to the highaffinity M-type receptor for secreted phospholipases $A_{2}$ is not obligatory for the presynaptic neurotoxicity of ammodytoxin A. Biochimie, Vol. 88, No. 10, pp. 14251433

Prijatelj, P., Jenko Pražnikar, Z., Petan, T., Križaj, I. \& Pungerčar, J. (2008). Mapping the structural determinants of presynaptic neurotoxicity of snake venom phospholipases A. Toxicon, Vol. 51, No. 8, pp. 1520-1529

Pungerčar, J., Liang, N.S., Štrukelj, B. \& Gubenšek, F. (1990). Nucleotide sequence of a cDNA encoding ammodytin L. Nucleic Acids Research, Vol. 18, No. 15, p. 4601

Pungerčar, J., Križaj, I., Liang, N.S. \& Gubenšek, F. (1999). An aromatic, but not a basic, residue is involved in the toxicity of group-II phospholipase $\mathrm{A}_{2}$ neurotoxins. Biochemical Journal, Vol. 341, Pt. 1, pp. 139-145

Pungerčar, J. \& Križaj, I. (2007). Understanding the molecular mechanism underlying the presynaptic toxicity of secreted phospholipases $A_{2}$. Toxicon, Vol. 50, No. 7, pp. 871892

Ramirez, F. \& Jain, M.K. (1991). Phospholipase $A_{2}$ at the bilayer interface. Proteins: Structure, Function, and Bioinformatics, Vol. 9, No. 4, pp. 229-239 
Renetseder, R., Brunie, S., Dijkstra, B.W., Drenth, J. \& Sigler, P.B. (1985). A comparison of the crystal structures of phospholipase $\mathrm{A}_{2}$ from bovine pancreas and Crotalus atrox venom. Journal of Biological Chemistry, Vol. 260, No. 21, pp. 11627-11634

Rigoni, M., Caccin, P., Gschmeissner, S., Koster, G., Postle, A.D., Rossetto, O., Schiavo, G. \& Montecucco, C. (2005). Equivalent effects of snake $\mathrm{PLA}_{2}$ neurotoxins and lysophospholipid-fatty acid mixtures. Science, Vol. 310, No. 5754, pp. 1678-1680

Rigoni, M., Paoli, M., Milanesi, E., Caccin, P., Rasola, A., Bernardi, P. \& Montecucco, C. (2008). Snake phospholipase $A_{2}$ neurotoxins enter neurons, bind specifically to mitochondria, and open their transition pores. Journal of Biological Chemistry, Vol. 283, No. 49, pp. 34013-34020

Rosenberg, P. (1997) Pitfalls to avoid in the study of correlations between enzymatic activity and pharmacological properties of phospholipase $\mathrm{A}_{2}$ enzymes, In: Venom Phospholipase $A_{2}$ Enzymes: Structure, Function and Mechanism (Kini, R. M., Ed.), pp. 155-183, John Wiley \& Sons, Chichester, England.

Rouault, M., Rash, L.D., Escoubas, P., Boilard, E., Bollinger, J., Lomonte, B., Maurin, T., Guillaume, C., Canaan, S., Deregnaucourt, C., Schrével, J., Doglio, A., Gutiérrez, J.M., Lazdunski, M., Gelb, M.H. \& Lambeau, G. (2006). Neurotoxicity and other pharmacological activities of the snake venom phospholipase $\mathrm{A}_{2} \mathrm{OS}_{2}$ : The $\mathrm{N}$ terminal region is more important than enzymatic activity. Biochemistry, Vol. 45, No. 18 , pp. $5800-5816$

Rufini, S., Cesaroni, P., Desideri, A., Farias, R., Gubenšek, F., Gutiérrez, J.M., Luly, P., Massoud, R., Morero, R. \& Pedersen, J.Z. (1992). Calcium ion independent membrane leakage induced by phospholipase-like myotoxins. Biochemistry, Vol. 31, No. 49, pp. 12424-12430

Saul, F.A., Prijatelj-Žnidaršič, P., Vulliez-le Normand, B., Villette, B., Raynal, B., Pungerčar, J., Križaj, I. \& Faure, G. (2010). Comparative structural studies of two natural isoforms of ammodytoxin, phospholipases $\mathrm{A}_{2}$ from Vipera ammodytes ammodytes which differ in neurotoxicity and anticoagulant activity. Journal of Structural Biology, Vol. 169, No. 3, pp. 360-369

Scott, D.L., White, S.P., Otwinowski, Z., Yuan, W., Gelb, M.H. \& Sigler, P.B. (1990). Interfacial catalysis: The mechanism of phospholipase $\mathrm{A}_{2}$. Science, Vol. 250, No. 4987, pp. 1541-1546

Scott, D.L., Mandel, A.M., Sigler, P.B. \& Honig, B. (1994). The electrostatic basis for the interfacial binding of secretory phospholipases $\mathrm{A}_{2}$. Biophysical Journal, Vol. 67, No. 2, pp. 493-504

Singer, A.G., Ghomashchi, F., Le Calvez, C., Bollinger, J., Bezzine, S., Rouault, M., Sadilek, M., Nguyen, E., Lazdunski, M., Lambeau, G. \& Gelb, M.H. (2002). Interfacial kinetic and binding properties of the complete set of human and mouse groups I, II, V, X, and XII secreted phospholipases A2. Journal of Biological Chemistry, Vol. 277, No. 50, pp. 48535-48549

Snitko, Y., Koduri, R.S., Han, S.K., Othman, R., Baker, S.F., Molini, B.J., Wilton, D.C., Gelb, M.H. \& Cho, W. (1997). Mapping the interfacial binding surface of human secretory group IIa phospholipase A2. Biochemistry, Vol. 36, No. 47, pp. 14325-14333

Soares, A.M., Andrião-Escarso, S.H., Bortoleto, R.K., Rodrigues-Simioni, L., Arni, R.K., Ward, R.J., Gutiérrez, J.M. \& Giglio, J.R. (2001). Dissociation of enzymatic and pharmacological properties of piratoxins-I and -III, two myotoxic phospholipases $\mathrm{A}_{2}$ from Bothrops pirajai snake venom. Archives of Biochemistry and Biophysics, Vol. 387, No. 2, pp. 188-196 
Šribar, J., Čopič, A., Pariš, A., Sherman, N.E., Gubenšek, F., Fox, J.W. \& Križaj, I. (2001). A high affinity acceptor for phospholipase $\mathrm{A}_{2}$ with neurotoxic activity is a calmodulin. Journal of Biological Chemistry, Vol. 276, No. 16, pp. 12493-12496

Šribar, J., Čopič, A., Poljšak-Prijatelj, M., Kuret, J., Logonder, U., Gubenšek, F. \& Križaj, I. (2003a). R25 is an intracellular membrane receptor for a snake venom secretory phospholipase A2. FEBS Letters, Vol. 553, No. 3, pp. 309-314

Šribar, J., Sherman, N.E., Prijatelj, P., Faure, G., Gubenšek, F., Fox, J.W., Aitken, A., Pungerčar, J. \& Križaj, I. (2003b). The neurotoxic phospholipase $\mathrm{A}_{2}$ associates, through a non-phosphorylated binding motif, with 14-3-3 protein $\gamma$ and $\varepsilon$ isoforms. Biochemical and Biophysical Research Communications, Vol. 302, No. 4, pp. 691-696

Šribar, J., Anderluh, G., Fox, J.W. \& Križaj, I. (2005). Protein disulphide isomerase binds ammodytoxin strongly: Possible implications for toxin trafficking. Biochemical and Biophysical Research Communications, Vol. 329, No. 2, pp. 733-737

Stahelin, R.V. \& Cho, W. (2001). Differential roles of ionic, aliphatic, and aromatic residues in membrane-protein interactions: A surface plasmon resonance study on phospholipases A2. Biochemistry, Vol. 40, No. 15, pp. 4672-4678

Sumandea, M., Das, S., Sumandea, C. \& Cho, W. (1999). Roles of aromatic residues in high interfacial activity of Naja naja atra phospholipase A2. Biochemistry, Vol. 38, No. 49, pp. 16290-16297

Thouin, L.G., Ritonja, A., Gubenšek, F. \& Russell, F.E. (1982). Neuromuscular and lethal effects of phospholipase A from Vipera ammodytes venom. Toxicon, Vol. 20, No. 6, pp. 1051-1058

Tzeng, M.C., Yen, C.H., Hseu, M.J., Dupureur, C.M. \& Tsai, M.D. (1995). Conversion of bovine pancreatic phospholipase $\mathrm{A}_{2}$ at a single site into a competitor of neurotoxic phospholipases $\mathrm{A}_{2}$ by site-directed mutagenesis. Journal of Biological Chemistry, Vol. 270, No. 5, pp. 2120-2123

Valentin, E. \& Lambeau, G. (2000). What can venom phospholipases $A_{2}$ tell us about the functional diversity of mammalian secreted phospholipases $\mathrm{A}_{2}$ ? Biochimie, Vol. 82, No. 9-10, pp. 815-831

Vardjan, N., Sherman, N.E., Pungerčar, J., Fox, J.W., Gubenšek, F. \& Križaj, I. (2001). Highmolecular-mass receptors for ammodytoxin in pig are tissue-specific isoforms of Mtype phospholipase $\mathrm{A}_{2}$ receptor. Biochemical and Biophysical Research Communications, Vol. 289, No. 1, pp. 143-149

Vučemilo, N., Čopič, A., Gubenšek, F., \& Križaj, I. (1998). Identification of a new highaffinity binding protein for neurotoxic phospholipases $\mathrm{A}_{2}$. Biochemical and Biophysical Research Communications, Vol. 251, No. 1, pp. 209-212

Ward, R.J., Chioato, L., De Oliveira, A.H.C., Ruller, R. \& Sá, J.M. (2002). Active-site mutagenesis of a Lys49-phospholipase $\mathrm{A}_{2}$ : Biological and membrane-disrupting activities in the absence of catalysis. Biochemical Journal, Vol. 362, Pt. 1, pp. 89-96

Yau, W.M., Wimley, W.C., Gawrisch, K. \& White, S.H. (1998). The preference of tryptophan for membrane interfaces. Biochemistry, Vol. 37, No. 42, pp. 14713-14718

Yu, B.Z., Berg, O.G. \& Jain, M.K. (1993). The divalent cation is obligatory for the binding of ligands to the catalytic site of secreted phospholipase $A_{2}$. Biochemistry, Vol. 32, No. 25, pp. 6485-6492 